\title{
Characterization of DNA G-quadruplex Topologies with NMR Chemical Shifts
}

\author{
Rajesh Kumar Reddy Sannapureddi, Manish Kumar Mohanty, Anoop Kumar Gautam, and \\ Bharathwaj Sathyamoorthy* \\ Department of Chemistry, Indian Institute of Science Education and Research Bhopal, Madhya \\ Pradesh, India - 462066 \\ Email: bharathwaj@iiserb.ac.in
}

\section{$\underline{\text { Supporting Information }}$}

Figure S1: Formation of G-tetrads: from secondary to tertiary structure.

Methods: $\quad$ Mining of structural and chemical shift data

Table S1: $\quad$ List of PDB IDs for structures classified based on the backbone topology

Methods: $\quad$ Sample preparation and NMR methods

Table S2: $\quad$ List of samples prepared towards ${ }^{13} \mathrm{C}$ chemical shift analysis for $\mathrm{G}($ anti) and $\mathrm{G}(\mathrm{syn})$ characterization

Figure S2: $\quad$ Histogram of chemical shifts sampled by $\mathrm{G}($ anti) and $\mathrm{G}(\mathrm{syn})$ bases involved in tetrad formation.

Figure S3: Two-dimensional correlation of (A) N1-H1, (B) C2'-H2" and (C) C2'-H2'

Figure S4: (A) Sugar pucker preferences for $\mathrm{G}($ anti) and $\mathrm{G}(\mathrm{syn})$ bases forming the tetrad. (B) $\chi$-angle preferences of $\mathrm{G}($ anti) bases present 3 '-end to one (1-nt) and more than one (>1nt) nucleotide loops.

Table S3: Distribution of trinucleotide glycosidic torsion angle steps for various topologies

Figure S5: $\quad$ Two-dimensional ${ }^{1} \mathrm{H}^{-1} \mathrm{H}$ correlation of chemical shifts across the tetrad planes.

Methods: Details of variance analysis

Table S4: $\quad$ Variance analysis of chemical shifts towards structural characterization

Methods: Details of comparing performance of machine learning protocols.

Figure S6: $\quad$ Performance of machine learning protocols towards predicting G-tetrad pseudo plane information

Methods: Details of SVM protocol

Figure S7: $\quad$ Benchmarking and performance of SVM towards prediction of SVM

Table S5: $\quad$ Details of success of prediction for structural parameters using ${ }^{1} \mathrm{H}$ chemical shifts.

Figure S8: $\quad$ NOESY cross-peak assignment of $\mathrm{GGG}^{\mathrm{TT}}$ in potassium and sodium buffer conditions.

Table S6: Chemical shifts tables

BIBLIOGRAPHY 


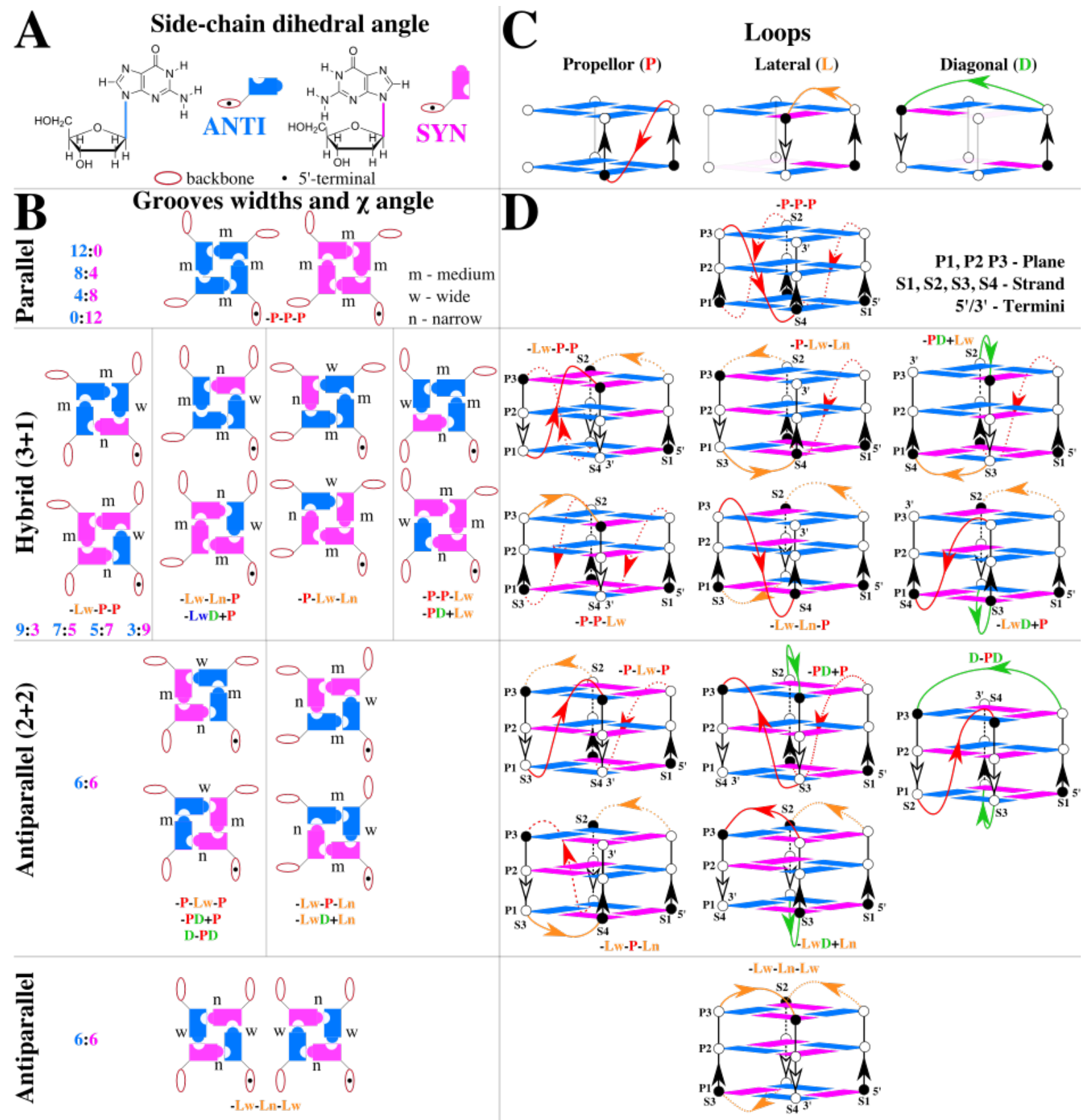

Figure S1: Formation of G-tetrads: from secondary to tertiary structure. (A) Schematic depiction of anti/syn bases. (B) Groove widths driving glycosidic torsion angle with plausible $\mathrm{G}($ anti): $\mathrm{G}($ syn $)$ ratios. (C) Schematic representation of loop conformations. Clockwise and counterclockwise orientation of loops are denoted by "+" and "-", respectively. (D) 13 possible tertiary structure folds of G-quadruplexes along with loop nomenclature represented with the first two strands in the "-" direction. 13 more are possible with the first two strands in "+" direction. ${ }^{1}$ Of the 26 possible structures, 14 feasible structures ${ }^{2}$ are parallel: -P-P-P; hybrid (3+1): +L+P+P, -L-L-P, -P-P-L, -P-L-L, +LD-P, -PD+L,; antiparallel (2+2): $\mathrm{PD}+\mathrm{P},+\mathrm{L}+\mathrm{P}+\mathrm{L}, \mathrm{D}+\mathrm{PD},-\mathrm{LD}+\mathrm{L}$ and $+\mathrm{LD}-\mathrm{L}$; antiparallel: $+\mathrm{L}+\mathrm{L}+\mathrm{L},-\mathrm{L}-\mathrm{L}-\mathrm{L}$. 
Methods: Mining of structural and chemical shift data

Mining for G-quadruplex (GQ) NMR structures: Protein data bank (PDB) was queried for GQ NMR structures. The 193 identified GQ structures (till June 2020) included DNA+RNA complex, RNA, DNAprotein complex, tetra-, bi- and uni-molecular structures. In order to expand in future towards loop conformations analysis, the 141 unimolecular GQ structures were probed further. This consisted of 32 two-plane, 97 three-plane and 12 four-plane GQs. Three-plane GQs deposited were further analysed for structural features. X3-DNA DSSR software ${ }^{3}$ was used to annotate structural features. The features were then parsed using an in-house python program. Various parameters including, but not limited to, overall topology, loop type, sequence specific glycosidic torsional angle of tetrad forming guanine nucleotides, strand orientation, were then extracted from the output and a database was created for further analysis.

Mining for chemical shift data: Among the three-plane GQ structures, ${ }^{13} \mathrm{C}$ and ${ }^{1} \mathrm{H}$ chemical shifts were mined from the Biological Magnetic Resonance Bank (BMRB) for data deposited until June 2020. Chemical shift data were obtained from BMRB for 69 out of the 97 GQ structures. Of these 69 structures, 4 dimer-quadruplexes, 1 DNA-protein, 1 non-canonical space filling quadruplex, 1 RNA complex were removed. Chemical shift information from BMRB for the remaining 62 GQs were then collated with their respective structures in the previously created database. Along with 62 datasets from BMRB, 6 datasets were collected from literature (PDB ID: $143 \mathrm{D},{ }^{4} 2 \mathrm{HY} 9,{ }^{5} 2 \mathrm{JSK},{ }^{6} 2 \mathrm{JSQ},{ }^{6} 2 \mathrm{KYP},{ }^{7} 6 \mathrm{JJ} 0^{8}$ ). It is to be noted that, while all the 68 structures had ${ }^{1} \mathrm{H}$ shifts, only $15 \mathrm{GQs}$ possessed ${ }^{13} \mathrm{C}$ chemical shift data. Of all the ${ }^{13} \mathrm{C}$ chemical shifts data available, only for three structures $\left(2 \mathrm{LPW},{ }^{9} 6 \mathrm{~T} 51,{ }^{10} 6 \mathrm{SUU}^{11}\right) \mathrm{C} 1$ ' shifts were reported, while for others only $\mathrm{C} 8$ nucleobase shifts were reported. These were available for five parallel (PDB ID: 2LPW, ${ }^{9} 6 \mathrm{NEB},{ }^{12}$ 6T51, ${ }^{10}$ 6T2G, ${ }^{11} 6 \mathrm{SUU}^{11}$ ), nine hybrid $(3+1)$ (PDB ID: 5MCR, ${ }^{13}$ 5O4D, ${ }^{14}$ $5 \mathrm{OV} 2,{ }^{15} 6 \mathrm{FFR},{ }^{16} 5 \mathrm{MBR},{ }^{13} 6 \mathrm{RS} 3,{ }^{17} 6 \mathrm{R} 9 \mathrm{~L},{ }^{18} 6 \mathrm{TC} 8,{ }^{19} 6 \mathrm{TCG}^{19}$ ) and one $(2+2)$ anti-parallel (PDB ID: $6 \mathrm{~F} 4 \mathrm{Z}^{20}$ ) topologies. Table S1 provides further details about the PDB entries in terms of modifications if present and the methodology used for structure determination (X-ray or NMR). While the parallel structures contained the exclusive canonical 2'-deoxyriboseguanosine, the hybrid and antiparallel possessed one or more 2'-fluoro-2'-deoxyriboseguanosine modification to stabilize a single dominant topology in solution. Although another $(2+2)$ antiparallel structure (ligand bound form of 143D) reported ${ }^{13} \mathrm{C}-{ }^{1} \mathrm{H}$ heteronuclear spectra in their publication, ${ }^{21}$ they were not used due to lack of tools to derive chemical shifts from the reported spectra. Due to a plausible chemical shift referencing issue, 2LPW $\left(\mathrm{C} 1^{\prime}\right)$, 6SUU $\left(\mathrm{C}^{\prime} / \mathrm{C} 2^{\prime} / \mathrm{C} 8\right), 6 \mathrm{~T} 2 \mathrm{G}(\mathrm{C} 8)$ and $6 \mathrm{~T} 51\left(\mathrm{C} 1^{\prime} / \mathrm{C} 2^{\prime} / \mathrm{C} 8\right)$ were not used for analysis. In total, heteronuclear C8/N1 shifts of $91 / 35$ and $33 / 01$ for the anti and syn orientations, respectively, were available (excluding nucleotides with any modifications). 
Python program for data analysis: The program to analyse chemical shifts was written with python (version 3). The program uses $x l r d$ library to search and print the chemical shifts of selected atom for all position of the nucleobase in the primary sequence involved in the tetrad formation for all PDB IDs. The function, in addition, also queries for the glycosidic torsion angle (anti versus syn) of that nucleobase. Using the data stored as arrays matplotlib plots the desired histograms, with blue and magenta coloured bars for anti and syn bases, respectively. The bin width for the histogram plots were 0.04 and $0.2 \mathrm{ppm}$ for ${ }^{1} \mathrm{H}$ and ${ }^{13} \mathrm{C} /{ }^{15} \mathrm{~N}$, respectively. The mean and the one-standard deviation for chosen dataset is displayed along with the number of data points present for anti and syn bases in the queried dataset. Twodimensional correlation plots were prepared with matplotlib. If either of the shifts were missing/unassigned for a given entry, then the data point is omitted from plotting. 


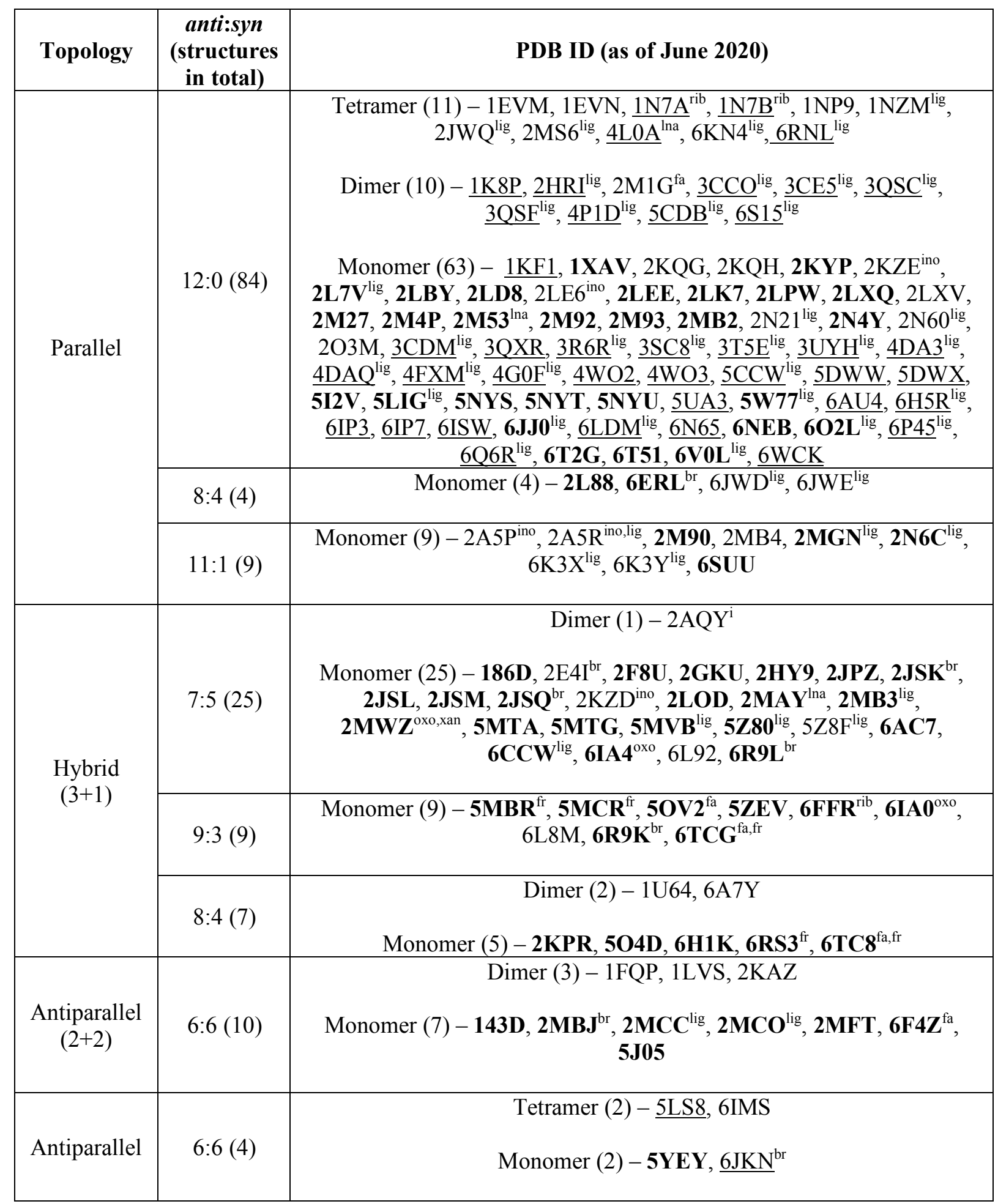

Table S1: List of PDB IDs for structures classified based on the backbone topology. X-ray crystal structures are underlined and NMR data used for chemical shift analysis are indicated in bold. Modifications are indicated as ${ }^{\text {fa) }}$ ''-fluoro-arabinose-guanosine modification, ${ }^{\text {fr) }} 2$ '-fluoro-ribose-guanosine modification ${ }^{\text {lna) }}$ locked sugar with guanosine base modification, ${ }^{\text {rib) }}$ ribose with guanosine base, ${ }^{\text {br) }} 8$ bromoguanosine modification, ino)inosine base, ${ }^{\text {oxo) }} 8$-oxoguanosine modification, ${ }^{x a n)}$ xanthine modification, ${ }^{\text {lig) }}$ ligand complex. 
Methods: Sample preparation and NMR methods

Sample preparation: DNA oligonucleotides were synthesized $(1 \mu$ mole scale $)$ in-house with K\&A DNA/RNA synthesizer using standard phosphoramidite chemistry or purchased (sequences 2JSL and 2JSM) from Integrated DNA Technologies as singles stranded DNA with standard desalting purification. All the reagents (CapA, CapB, oxidiser, trichloroacetic acid, ETT activator, acetonitrile, phosphoramidites, ammonium hydroxide, methylamine, sodium phosphate, potassium phosphate, sodium chloride, potassium chloride) were procured from Sigma-Aldrich and used without further purification. Synthesized oligonucleotides were cleaved and deprotected using the 1:1 aqueous ammonium hydroxide: methylamine solution for 2 hours at $37{ }^{\circ} \mathrm{C}$. Oligonucleotides were purified and desalted using reverse phase $1 \mathrm{~mL}$ Sep-Pak C18 columns (Water Inc.) with 50\% acetonitrile as eluent. Samples were evaporated to dryness using Speed-Vac at $45^{\circ} \mathrm{C}$ for a period of 6 hours. The dried oligonucleotides were dissolved in $500 \mu \mathrm{L}$ of nanopore water. Single-strand DNA concentrations were estimated with absorbance at $260 \mathrm{~nm}$ measured using Shimadzu UV-1800 UV-VIS spectrophotometer. Molar absorptivity was estimated using nearest neighbor model obtained from IDT DNA online tool (https://eu.idtdna.com/calc/analyzer). Oligonucleotides solutions were resuspended to $\sim 7-9 \mathrm{~mL}$ of nanopure water and annealed by heating at $95{ }^{\circ} \mathrm{C}$ for 5 minutes, followed by addition of $10 \mathrm{X}$ potassium (or sodium) phosphate buffer along with $1 \mathrm{M}$ $\mathrm{KCl}$ (or $\mathrm{NaCl}$ ) stock to make $\sim 10 \mathrm{~mL}$ oligo solution in NMR buffer (1X phosphate buffer, salt, $0.1 \mathrm{mM}$ ethylenediaminetetraacetic acid). This mixture was further heated at $95{ }^{\circ} \mathrm{C}$ for 5 minutes and kept for slow cooling at room temperature overnight. The annealed samples were concentrated and washed with the NMR buffer using the centrifugal concentrators (Amicon, Merck Inc., $3 \mathrm{kDa}$ cutoff) at $4000 \mathrm{~g}$ and $4{ }^{\circ} \mathrm{C}$. The concentrated samples were made to $275 \mu \mathrm{L}$ by addition of NMR buffer, $\mathrm{D}_{2} \mathrm{O}$ (final $5 \% \mathrm{v} / \mathrm{v}$ ), trimethylsilylpropanoic standard (TSP, $50 \mu \mathrm{M}$ ) and transferred to $5 \mathrm{~mm}$ Shigemi NMR tubes and used for acquiring NMR data. List of samples prepared are provided in Table S2.

NMR methods: All NMR data were acquired on $700 \mathrm{MHz}$ proton precession frequency Bruker spectrometer equipped with AVANCE III console, cryogenic triple ${ }^{1} \mathrm{H},{ }^{13} \mathrm{C},\left\{{ }^{15} \mathrm{~N}\right\}$ resonance $5 \mathrm{~mm}$ probe with z-axis pulsed field gradients. All data were acquired at $298 \mathrm{~K}$ and chemical shift referenced with internal TSP standard. Two-dimensional (2D) ${ }^{1} \mathrm{H}-{ }^{1} \mathrm{H}$ NOESY ${ }^{22}$ spectra were acquired using standard Bruker program with 3-9-19 water suppression scheme (noesygpph19). Acquisition parameters recycle delay of $2.5 \mathrm{~s}$, mixing time of $200 \mathrm{~ms}$ and indirect dimension evolution time of 40-50 ms were set. 2D ${ }^{13} \mathrm{C}-{ }^{1} \mathrm{H}$ heteronuclear single quantum coherence ${ }^{22}$ (HSQC) spectrum were acquired using Bruker program (hsqcetgpsisp2.2) employing adiabatic CHIRP pulses and GARP decoupling during acquisition, modified with a water flip-back pulse. The carrier and spectral width were set at 80 and 14 ppm, respectively, so as 
to effectively alias the aromatic, $\mathrm{C} 2{ }^{\prime}-\mathrm{H} 2^{\prime} / \mathrm{H} 2 "$ and methyl resonances with minimal interference obtaining all ${ }^{13} \mathrm{C}-{ }^{1} \mathrm{H}$ correlations in a single experiment. Aliased shifts were carefully set during data analysis. Acquisition parameters recycle delay of $1.5 \mathrm{~s}$ and direct and indirect dimension evolution time of 32-64 and $100 \mathrm{~ms}$, respectively, were set. Band-selective flip angle optimized short transient (SOFAST-) heteronuclear multiple quantum coherence (HMQC) spectra were obtained for ${ }^{15} \mathrm{~N}-{ }^{1} \mathrm{H}$ correlations ${ }^{23}$ using Bruker program (sfhmqcf3gpph). Recycle delay of $400 \mathrm{~ms}$, with spectral width and carrier positions of 6 and $143.5 \mathrm{ppm}$, respectively, were set. ${ }^{1} \mathrm{H}$ selective excitation and refocusing were performed with PC9 pulse with $120^{\circ}$ flip angle and RSNOB pulses was centered at $11.2 \mathrm{ppm}$ with an excitation bandwidth of 5 ppm, with GARP pulses for decoupling during acquisition. All data were acquired on TopSpin v3.5pl6 (Bruker Inc.), processed using NMRPipe ${ }^{24}$ and analyzed using NMRFAM-SPARKY. ${ }^{25}$ The 2D NOESY and HSQC measurement times for each sample is provided in Table S2.

Integrating newly acquired chemical shifts into database: The number of parallel, hybrid $(3+1)$, antiparallel $(2+2)$ and fully antiparallel topologies were five (PDB ID: $1 \mathrm{XAV}^{26}$ four new samples in $\mathrm{K}^{+}$ buffer: $\mathrm{GGG}^{\mathrm{A}}, \mathrm{GGG}^{\mathrm{T}}, \mathrm{GGG}^{\mathrm{TT}}, \mathrm{GGG}^{\mathrm{AT}}$ ), twelve (PDB ID: $2 \mathrm{LOD},{ }^{27} 2 \mathrm{GKU}^{28}{ }^{28} 2 \mathrm{JSM},{ }^{6} 186 \mathrm{D},{ }^{29} 2 \mathrm{JPZ}^{30}$ $2 \mathrm{~F} 8 \mathrm{U},{ }^{31} 2 \mathrm{JSL},{ }^{6} 6 \mathrm{AC} 7,{ }^{32} 2 \mathrm{KPR}^{33}$ and $6 \mathrm{H}_{1} \mathrm{~K}^{34}$ and two additional samples $\mathrm{GGG}^{\mathrm{TT}}$ and $\mathrm{GGG}^{\mathrm{AT}}$ in sodium buffer), two (PDB ID: 2MFT, ${ }^{35} 5 \mathrm{~J}^{3} 5^{35}$ ) and one (PDB ID: 5YEY ${ }^{36}$ ), respectively. The details of their primary sequence and buffer conditions are listed in Table S2. In the above sequences, two "v-loop" containing hybrid (3+1) structures were also analysed (PDB ID: 2KPR and 6H1K). Except for the two sequences 2F8U (G21 C8 and C1') and 2JPZ (G16 C8, H8) that exhibited resonance broadening in the carbon dimension, all other ${ }^{13} \mathrm{C}$ shifts were successfully measured. In all, a total of $689{ }^{13} \mathrm{C}(238 \mathrm{C} 8,239$ $\mathrm{C1}^{\prime}, 212 \mathrm{C} 2$ ') shifts were added to the previously existing shifts (C8 only) expanding the repository by $\sim 83 \%$. Out of the total 238 shifts for C8 (164 anti, 74 syn), 239 shifts for C1' (164 anti, 75 syn), 212 shifts for C2' (145 anti, 67 syn) bases in the dataset. Furthermore, ${ }^{15} \mathrm{~N}$ imino shifts for the GQ planes were also integrated, in all 178 number of ${ }^{15} \mathrm{~N}$ imino shifts (122 anti, $56 \mathrm{syn}$ ) for guanosine nucleobases present in the tetrad plane were added to the database. 


\begin{tabular}{|c|c|c|c|c|c|c|c|c|c|}
\hline $\begin{array}{l}\text { S. } \\
\text { No }\end{array}$ & $\begin{array}{c}\text { PDB/ Sample } \\
\text { Name }\end{array}$ & Primary sequence $\left(5^{\prime}-\right.$ to $\left.3^{\prime}\right)$ & $\begin{array}{l}\text { Len } \\
\text { gth } \\
\text { (nt) }\end{array}$ & $\begin{array}{l}\text { Backbone } \\
\text { Topology }\end{array}$ & $\begin{array}{c}\text { Strand } \\
\text { Orientation* } \\
\text { (anti:syn) }\end{array}$ & $\begin{array}{c}\text { Loop } \\
\text { Conform- } \\
\text { ation } \dagger \\
\end{array}$ & $\begin{array}{l}\text { Conc. } \\
(\mathrm{mM})\end{array}$ & $\begin{array}{c}\text { Buffer }^{\%} \\
\text { (all samples had } 5 \% \text { D2O and } 0.1 \mathrm{mM} \\
\text { EDTA, } 50 \mu \mathrm{M} \text { TSP) }\end{array}$ & $\begin{array}{l}\text { NMR } \\
\text { time }+ \\
\text { (hours) }\end{array}$ \\
\hline 1 & $\mathrm{GGG}^{\mathrm{A}}\left(\mathrm{K}^{+}\right)$ & AAGGGAGGGAGGGAGGGAA & 19 & Parallel & UUUU (12:0) & -P-P-P & 2.0 & $20 \mathrm{mM} \mathrm{KPi} \mathrm{(pH} \mathrm{7),} 50 \mathrm{mM} \mathrm{KCl}$ & 7.75 \\
\hline 2 & $\mathrm{GGG}^{\mathrm{T}}\left(\mathrm{K}^{+}\right)$ & AAGGGTGGGTGGGTGGGAA & 19 & Parallel & UUUU (12:0) & -P-P-P & 2.7 & $20 \mathrm{mM} \mathrm{KPi} \mathrm{(pH} \mathrm{7),} 50 \mathrm{mM} \mathrm{KCl}$ & 7.75 \\
\hline 3 & 1XAV & TGAGGGTGGGTAGGGTGGGTAA & 22 & Parallel & UUUU (12:0) & -P-P-P & 1.4 & $25 \mathrm{mM} \mathrm{KPi} \mathrm{(pH} \mathrm{7),} 70 \mathrm{mM} \mathrm{KCl}$ & 8.75 \\
\hline 4 & $\mathrm{GGG}^{\mathrm{TT}}\left(\mathrm{K}^{+}\right)$ & AAGGGTTGGGTTGGGTTGGGAA & 22 & Parallel & UUUU (12:0) & -P-P-P & 1.5 & $20 \mathrm{mM} \mathrm{KPi} \mathrm{(pH} \mathrm{7),} 50 \mathrm{mM} \mathrm{KCl}$ & 9.75 \\
\hline 5 & $\mathrm{GGG}^{\mathrm{AT}}\left(\mathrm{K}^{+}\right)$ & AAGGGATGGGATGGGATGGGAA & 22 & Parallel & UUUU (12:0) & -P-P-P & 1.8 & $20 \mathrm{mM} \mathrm{KPi} \mathrm{(pH} \mathrm{7),} 50 \mathrm{mM} \mathrm{KCl}$ & 14.5 \\
\hline 6 & $186 \mathrm{D}$ & TTGGGGTTGGGGTTGGGGTTGGGG & 24 & Hybrid $(3+1)$ & UDUU (7:5) & $-\mathrm{L}_{\mathrm{w}}-\mathrm{L}_{\mathrm{n}}-\mathrm{P}$ & 1.2 & $20 \mathrm{mM} \mathrm{NaPi}(\mathrm{pH} 6.8$ ), $80 \mathrm{mM} \mathrm{NaCl}$ & 11 \\
\hline 7 & $2 \mathrm{~F} 8 \mathrm{U}$ & GGGCGCGGGAGGAATTGGGCGGG & 23 & Hybrid $(3+1)$ & UDUU (7:5) & $-\mathrm{L}_{\mathrm{w}}-\mathrm{L}_{\mathrm{n}}-\mathrm{P}$ & 0.8 & $20 \mathrm{mM} \mathrm{KPi} \mathrm{(pH} \mathrm{7),} 40 \mathrm{mM} \mathrm{KCl}$ & 29.25 \\
\hline 8 & $2 \mathrm{GKU}$ & TTGGGTTAGGGTTAGGGTTAGGGA & 24 & Hybrid $(3+1)$ & UUDU (7:5) & $-\mathrm{P}-\mathrm{L}_{\mathrm{w}}-\mathrm{L}_{\mathrm{n}}$ & 1.4 & $20 \mathrm{mM} \mathrm{KPi} \mathrm{(pH} \mathrm{7),} 70 \mathrm{mM} \mathrm{KCl}$ & 13.25 \\
\hline 9 & 2JPZ & TTAGGGTTAGGGTTAGGGTTAGGGTT & 26 & Hybrid $(3+1)$ & UDUU (7:5) & $-\mathrm{L}_{\mathrm{w}}-\mathrm{L}_{\mathrm{n}}-\mathrm{P}$ & 2.1 & $25 \mathrm{mM} \mathrm{KPi} \mathrm{(pH} \mathrm{7),} 70 \mathrm{mM} \mathrm{KCl}$ & 13.25 \\
\hline 10 & 2JSL & TAGGGTTAGGGTTAGGGTTAGGGTT & 25 & Hybrid $(3+1)$ & UDUU $(7: 5)$ & $-\mathrm{L}_{\mathrm{w}}-\mathrm{L}_{\mathrm{n}}-\mathrm{P}$ & 3.4 & $20 \mathrm{mM} \mathrm{KPi} \mathrm{(pH} \mathrm{7),} 70 \mathrm{mM} \mathrm{KCl}$ & 9.75 \\
\hline 11 & 2JSM & TAGGGTTAGGGTTAGGGTTAGGG & 23 & Hybrid $(3+1)$ & UUDU (7:5) & $-\mathrm{P}-\mathrm{L}_{\mathrm{w}}-\mathrm{L}_{\mathrm{n}}$ & 1.7 & $20 \mathrm{mM} \mathrm{KPi} \mathrm{(pH} \mathrm{7),} 70 \mathrm{mM} \mathrm{KCl}$ & 19.25 \\
\hline 12 & 2LOD & GGGATGGGACACAGGGGACGGG & 22 & Hybrid $(3+1)$ & UUUD (7:5) & $-\mathrm{P}-\mathrm{L}_{\mathrm{w}}-\mathrm{L}_{\mathrm{n}}$ & 1.6 & $10 \mathrm{mM} \mathrm{KPi} \mathrm{(pH} \mathrm{6.8),} 50 \mathrm{mM} \mathrm{KCl}$ & 17 \\
\hline 13 & $6 \mathrm{AC7}$ & TGGGGTCCGAGGCGGGGCTTGGG & 23 & Hybrid $(3+1)$ & UDUU (7:5) & $-\mathrm{L}_{\mathrm{w}}-\mathrm{L}_{\mathrm{n}}-\mathrm{P}$ & 1.0 & $20 \mathrm{mM} \mathrm{KPi} \mathrm{(pH} \mathrm{7),} 70 \mathrm{mM} \mathrm{KCl}$ & 8.75 \\
\hline 14 & $\mathrm{GGG}^{\mathrm{TT}}\left(\mathrm{Na}^{+}\right)$ & AAGGGTTGGGTTGGGTTGGGAA & 22 & Hybrid $(3+1)$ & UDUU $(7: 5)$ & $-\mathrm{L}_{\mathrm{w}}-\mathrm{L}_{\mathrm{n}}-\mathrm{P}$ & 2.4 & $20 \mathrm{mM} \mathrm{NaPi}(\mathrm{pH} 7), 50 \mathrm{mM} \mathrm{NaCl}$ & 8.75 \\
\hline 15 & $\mathrm{GGG}^{\mathrm{AT}}\left(\mathrm{Na}^{+}\right)$ & AAGGGATGGGATGGGATGGGAA & 22 & Hybrid $(3+1)$ & UDUU $(7: 5)$ & $-\mathrm{L}_{\mathrm{w}}-\mathrm{L}_{\mathrm{n}}-\mathrm{P}$ & 1.6 & $20 \mathrm{mM} \mathrm{NaPi}(\mathrm{pH} 7), 50 \mathrm{mM} \mathrm{NaCl}$ & 8.75 \\
\hline 16 & $2 \mathrm{KPR}^{\star}$ & GGGTGGGGAAGGGGTGGGT & 19 & Hybrid $(3+1)$ & UDDD (8:4) & $-\mathrm{L}_{\mathrm{w}} \mathbf{X}+\mathrm{P}$ & 1.5 & $5 \mathrm{mM} \mathrm{KPi} \mathrm{(pH} \mathrm{6.8),} 50 \mathrm{mM} \mathrm{KCl}$ & 11 \\
\hline 17 & $6 \mathrm{H} 1 \mathrm{~K}^{\star}$ & GGGAGGCGTGGCCTGGGCGGGACTGGGG & 28 & Hybrid $(3+1)$ & UDDD (8:4) & $\mathrm{D}+\mathrm{PX}$ & 0.9 & $20 \mathrm{mM} \mathrm{KPi} \mathrm{(pH} \mathrm{7),} 70 \mathrm{mM} \mathrm{KCl}$ & 14 \\
\hline 18 & 2MFT & GGGTTTTGGGTGGGTTTTGGG & 21 & $\begin{array}{c}\text { Antiparallel } \\
(2+2)\end{array}$ & UDDU (6:6) & $\mathrm{D}+\mathrm{PD}$ & 2.1 & 4 mM NaPi (pH 6.8), 16 mM NaCl & 8.75 \\
\hline 19 & $5 \mathrm{~J} 05$ & GGGTTTGGGTTTTGGGAGGG & 20 & $\begin{array}{c}\text { Antiparallel } \\
(2+2)\end{array}$ & UDDU (6:6) & $-\mathrm{L}_{\mathrm{w}} \mathrm{D}+\mathrm{L}_{\mathrm{n}}$ & 1.5 & $20 \mathrm{mM} \mathrm{NaPi}$ (pH 6.8), $80 \mathrm{mM} \mathrm{NaCl}$ & 12.5 \\
\hline 20 & $5 \mathrm{YEY}$ & GGGTTAGGGTTAGGGTTTGGG & 21 & Antiparallel & UDUD (6:6) & $+\mathrm{L}_{\mathrm{n}}+\mathrm{L}_{\mathrm{w}}+\mathrm{L}_{\mathrm{n}}$ & 1.4 & $20 \mathrm{mM} \mathrm{KPi} \mathrm{(pH} \mathrm{7),} 70 \mathrm{mM} \mathrm{KCl}$ & 13.25 \\
\hline
\end{tabular}

Table S2: List of samples prepared towards ${ }^{13} \mathrm{C}$ chemical shift analysis for $\mathrm{G}\left(\right.$ anti) and $\mathrm{G}(\mathrm{syn})$ characterization. ${ }^{\star}$ indicates hybrid $(3+1)$ with $\mathrm{v}$ loop and 8:4 anti:syn ratio. * Relative strand orientation provided with the first strand being in "up" (U) and strands antiparallel to this strand denoted as "down" (D). $\dagger$ loop conformation with counter-clockwise denoted as "minus" (-) and clockwise as "plus" (+), v-loop is denoted with "X". \% Buffer conditions with KPi and NaPi denoting potassium and sodium phosphate buffers, respectively. $¥$ NMR measurement time accounts for 2D NOESY and HSQC data acquisition. 

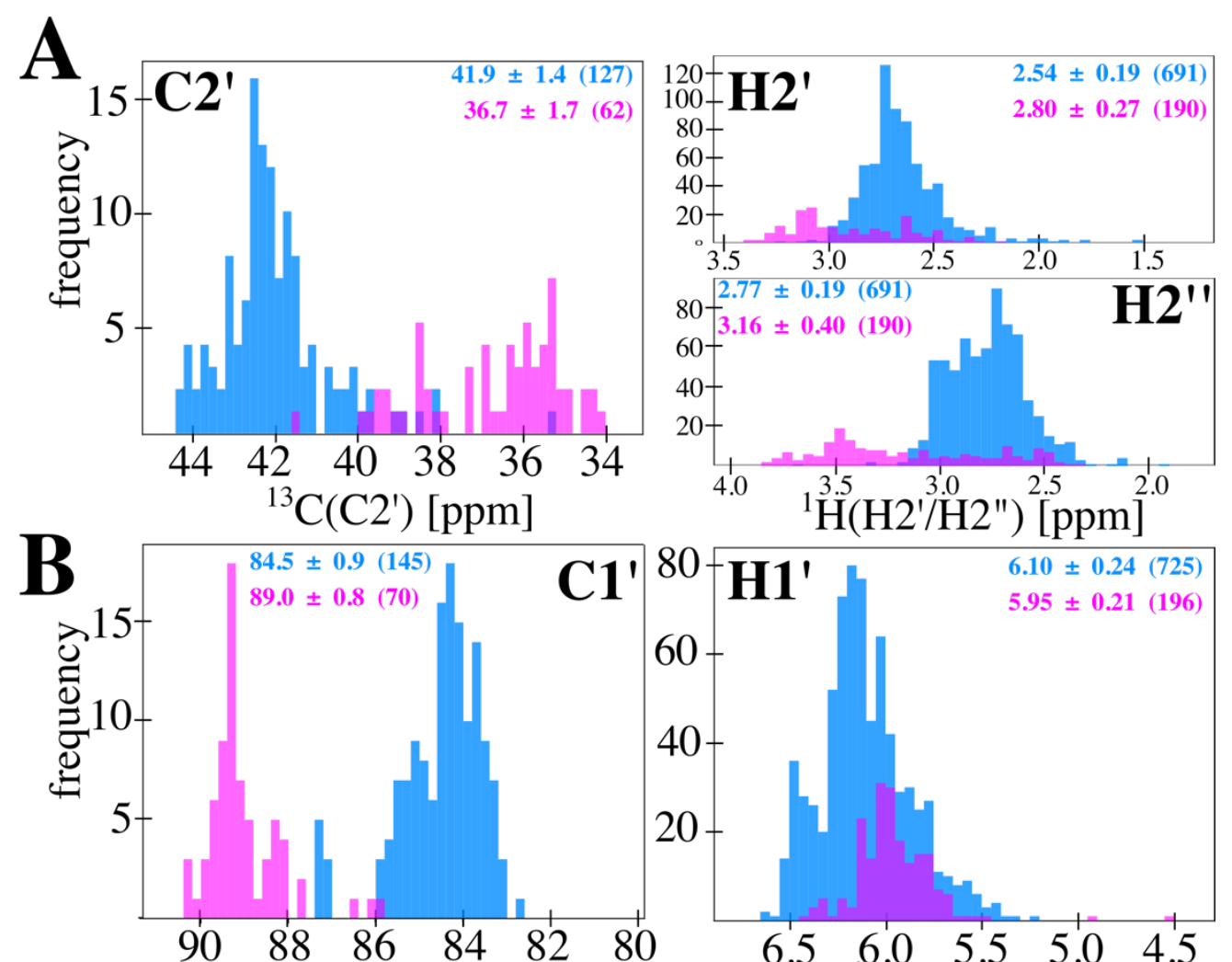

${ }^{1} \mathrm{H}\left(\mathrm{H} 2{ }^{1} / \mathrm{H} 2 "\right)[\mathrm{ppm}]$
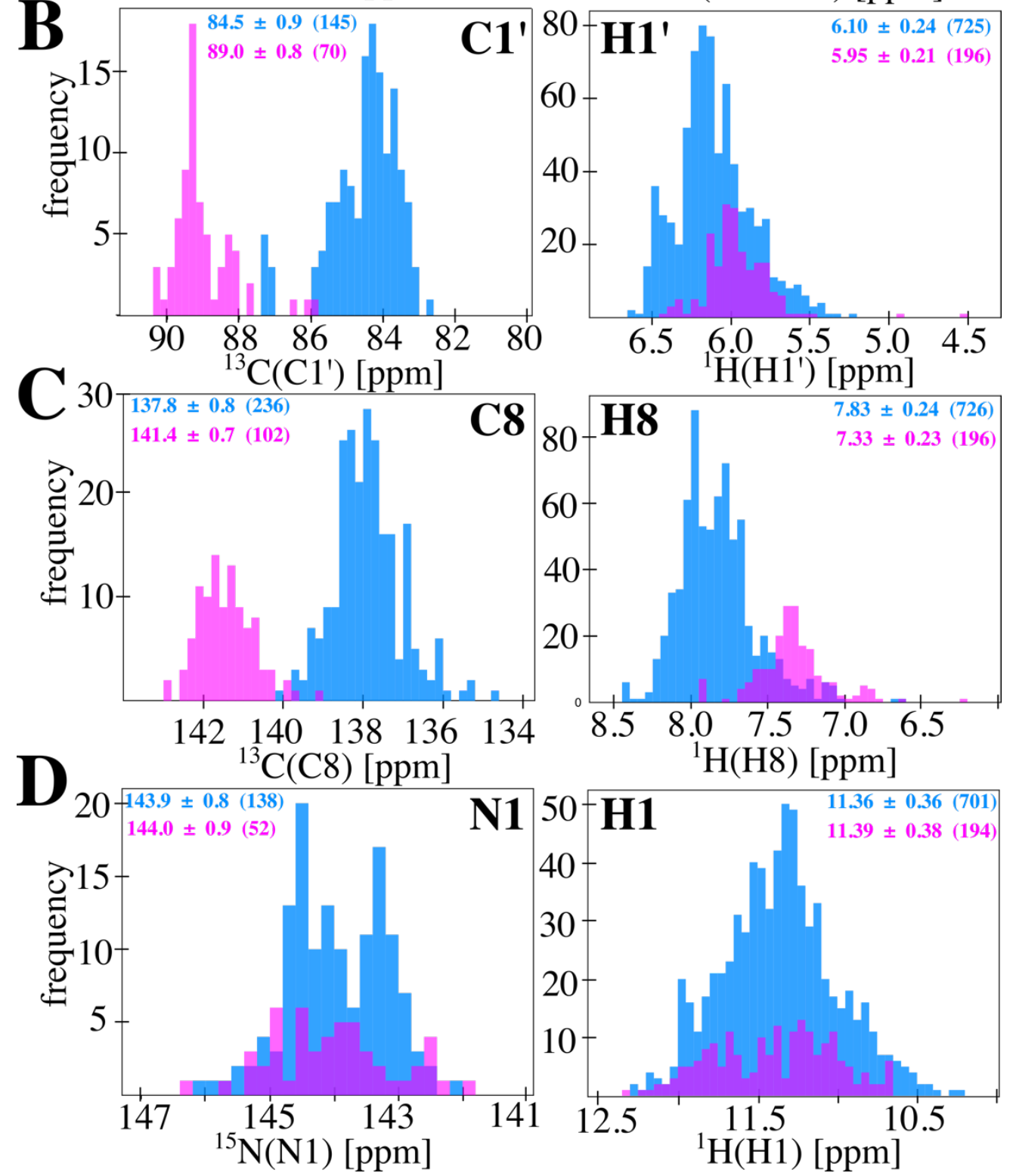

Figure S2: Histogram of chemical shifts sampled by $\mathrm{G}($ anti) and $\mathrm{G}(\mathrm{syn})$ bases involved in tetrad formation. 

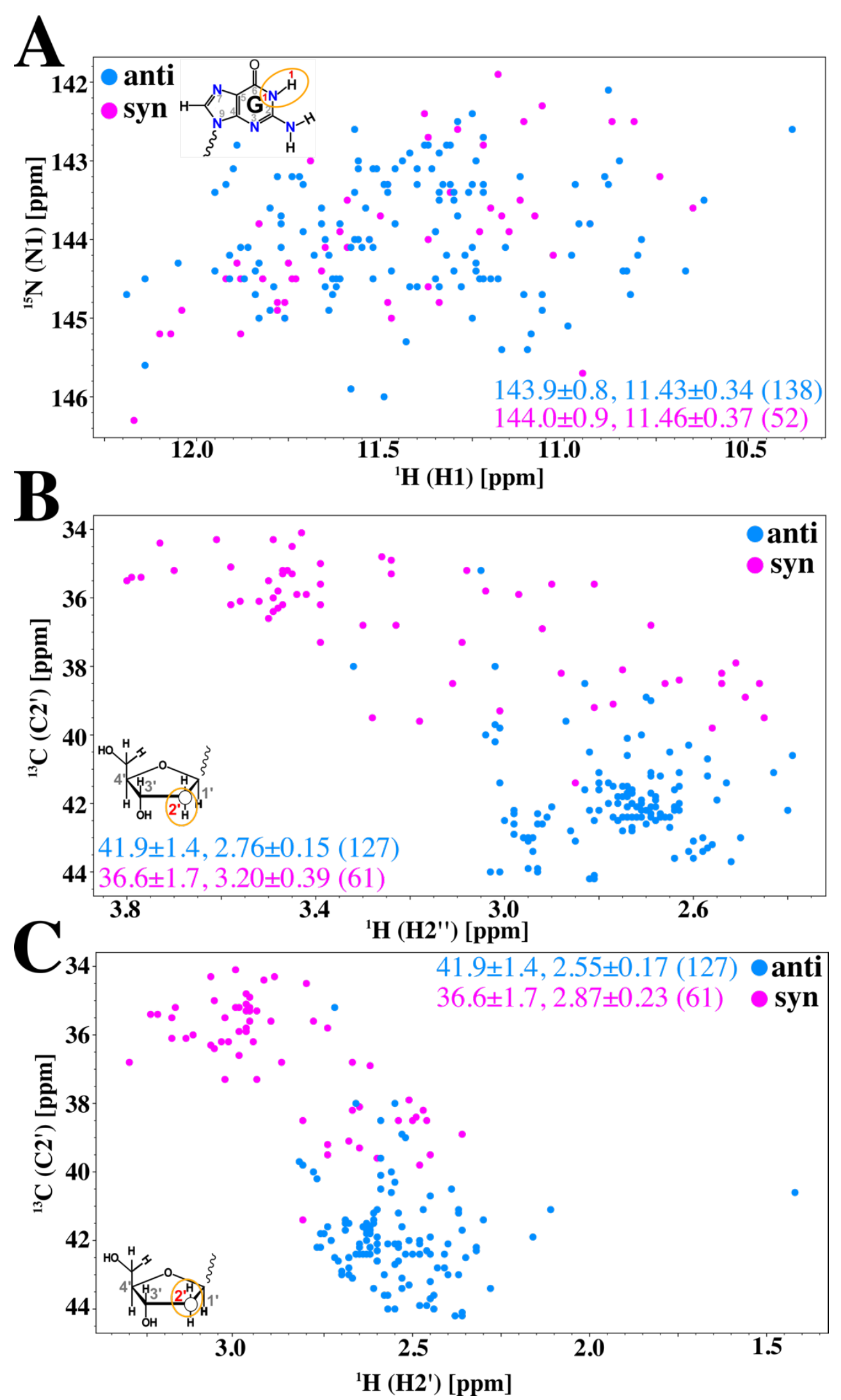

Figure S3: Two-dimensional correlation of (A) N1-H1, (B) C2'-H2" and (C) C2'-H2' 

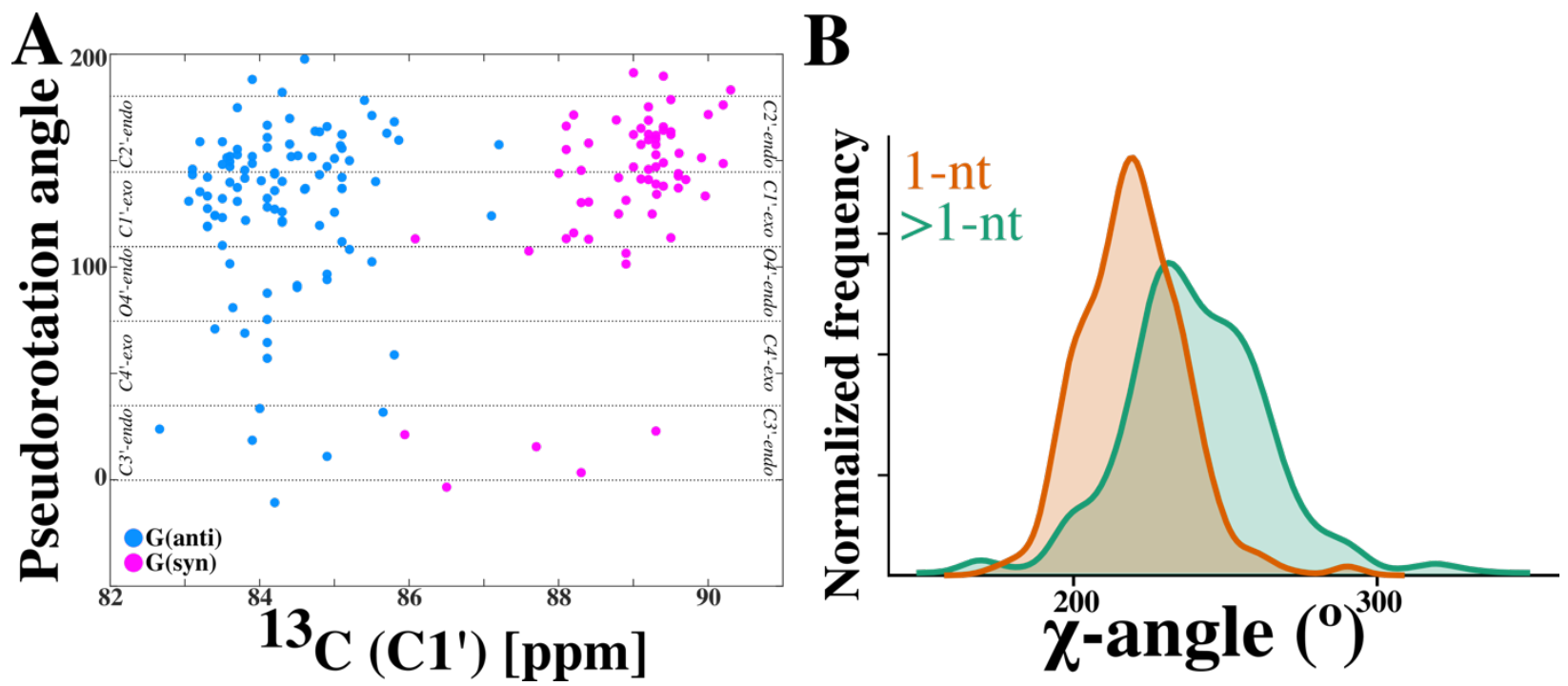

Figure S4: (A) Sugar pucker preferences for $\mathrm{G}(a n t i)$ and $\mathrm{G}(\mathrm{syn})$ bases forming the tetrad. Pseudorotation angle expressed in degrees. (B) $\chi$-angle preferences of $\mathrm{G}($ anti) bases present 3 '-end to one (1-nt) and more than one $(>1-n t)$ nucleotide loops.

\begin{tabular}{|c|c|c|c|c|}
\hline $\begin{array}{c}\text { Trinucleotide } \\
\text { glycosidic } \\
\text { torsion angle } \\
\text { (A= Anti } \\
\text { S= Syn) }\end{array}$ & Parallel & $\begin{array}{c}\text { Hybrid } \\
\mathbf{( 3 + 1}\end{array}$ & $\begin{array}{c}\text { Antiparallel } \\
\mathbf{( 2 + 2 )}\end{array}$ & Antiparallel \\
\hline A-A-A & 349 & 32 & None & None \\
\hline S-A-A & 16 & 94 & 10 & 8 \\
\hline A-S-A & None & None & 10 & None \\
\hline A-A-S & None & None & None & None \\
\hline S-S-A & None & 27 & 10 & 8 \\
\hline S-A-S & None & None & 10 & None \\
\hline A-S-S & None & None & None & None \\
\hline S-S-S & None & 6 & None & None \\
\hline $\begin{array}{c}\text { Note: No Strand discontinuity (except bulge). "None" implies no structure observed with } \\
\text { trinucleotide steps with that particular glycosidic torsion angle combination. }\end{array}$ \\
\hline
\end{tabular}

Table S3: Distribution of trinucleotide glycosidic torsion angle steps for various topologies 

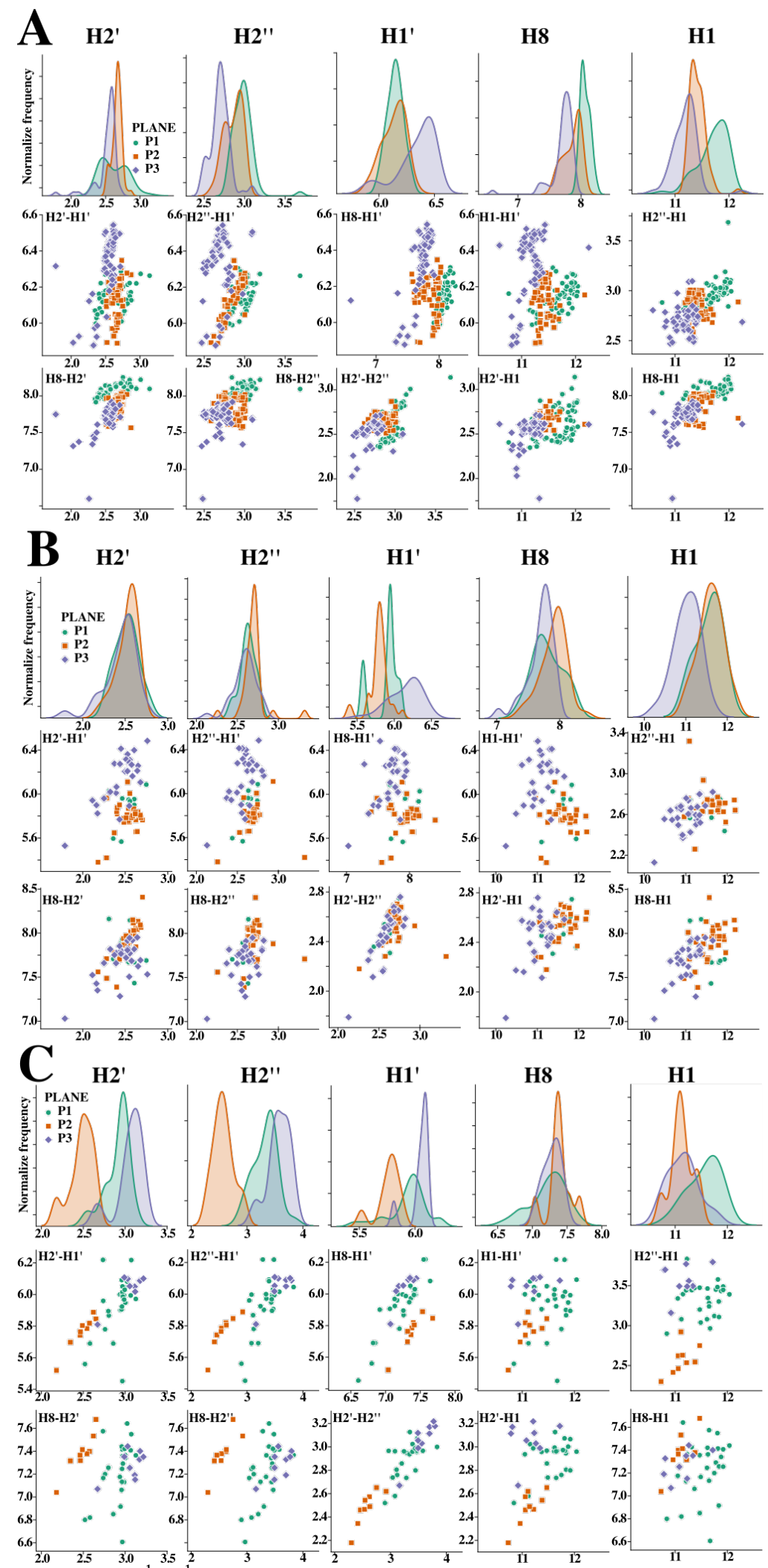

Figure S5: Two-dimensional ${ }^{1} \mathrm{H}-{ }^{1} \mathrm{H}$ correlation of chemical shifts across the tetrad planes. (A) Parallel, (B) Hybrid anti and (C) Hybrid syn. For all plots, x-axis represents chemical shift in ppm. 
Methods: Details of variance analysis.

One-way analysis of variance (ANOVA) and least significant difference (LSD) were performed using established protocols, employing statsmodels and pandas library in python (version 3.7.4) and T.INV.2T function in Microsoft excel spreadsheet program.

\begin{tabular}{|c|c|c|c|c|c|c|c|c|c|c|}
\hline \multirow{2}{*}{ Features } & \multirow{2}{*}{ Spin } & \multicolumn{3}{|c|}{ Parallel } & \multicolumn{3}{|c|}{ Hybrid syn } & \multicolumn{3}{|c|}{ Hybrid anti } \\
\hline & & F-value & LSD & AMD & F-value & LSD & AMD & F-value & LSD & AMD \\
\hline Plane 1-2 & \multirow{3}{*}{ H8 } & \multirow{3}{*}{97.13} & 0.25 & 1.02 & \multirow{3}{*}{1.62} & 0.77 & 0.69 & \multirow{3}{*}{4.97} & 0.77 & 0.41 \\
\hline Plane 2-3 & & & 0.25 & 0.71 & & 0.95 & 0.45 & & 0.55 & 0.86 \\
\hline Plane 1-3 & & & 0.25 & 1.73 & & 0.77 & 0.24 & & 0.77 & 0.45 \\
\hline Plane 1-2 & \multirow{3}{*}{ H1' } & \multirow{3}{*}{55.79} & 0.28 & 0.07 & \multirow{3}{*}{8.14} & 0.68 & 1.00 & \multirow{3}{*}{31.32} & 0.57 & 0.22 \\
\hline Plane 2-3 & & & 0.28 & 1.32 & & 0.84 & 1.65 & & 0.40 & 1.53 \\
\hline Plane 1-3 & & & 0.28 & 1.26 & & 0.68 & 0.65 & & 0.57 & 1.32 \\
\hline Plane 1-2 & \multirow{3}{*}{ H2' } & \multirow{3}{*}{15.85} & 0.33 & 0.29 & \multirow{3}{*}{39.10} & 0.48 & 1.78 & \multirow{3}{*}{1.16} & 0.82 & 0.38 \\
\hline Plane 2-3 & & & 0.33 & 0.91 & & 0.58 & 2.38 & & 0.58 & 0.42 \\
\hline Plane 1-3 & & & 0.33 & 0.62 & & 0.48 & 0.61 & & 0.82 & 0.04 \\
\hline Plane 1-2 & \multirow{3}{*}{ H2" } & \multirow{3}{*}{84.98} & 0.26 & 0.72 & \multirow{3}{*}{62.84} & 0.40 & 1.92 & \multirow{3}{*}{3.63} & 0.79 & 0.76 \\
\hline Plane 2-3 & & & 0.26 & 0.96 & & 0.49 & 2.55 & & 0.56 & 0.68 \\
\hline Plane 1-3 & & & 0.26 & 1.68 & & 0.40 & 0.63 & & 0.79 & 0.07 \\
\hline Plane 1-2 & \multirow{3}{*}{ H1 } & \multirow{3}{*}{88.82} & 0.25 & 0.95 & \multirow{3}{*}{11.39} & 0.65 & 1.25 & \multirow{3}{*}{22.77} & 0.62 & 0.25 \\
\hline Plane 2-3 & & & 0.25 & 0.75 & & 0.79 & 0.07 & & 0.44 & 1.43 \\
\hline \multirow{2}{*}{ Plane 1-3 } & & & 0.25 & 1.70 & & 0.65 & 1.17 & & 0.62 & 1.18 \\
\hline & & F-value & LSD & AMD & F-value & LSD & AMD & F-value & $\begin{array}{l}\text { LSD } \\
\end{array}$ & AMD \\
\hline Plane 1-2 & \multirow{3}{*}{ C1' } & \multirow{3}{*}{16.81} & 0.69 & 1.91 & \multirow{3}{*}{10.58} & 0.88 & 1.91 & \multirow{3}{*}{55.79} & 0.52 & 0.05 \\
\hline Plane 2-3 & & & 0.69 & 0.75 & & 1.08 & 1.24 & & 0.37 & 1.79 \\
\hline Plane 1-3 & & & 0.69 & 1.16 & & 0.88 & 0.68 & & 0.52 & 1.75 \\
\hline Plane 1-2 & & & 1.07 & 0.18 & & 1.02 & 1.65 & & 0.76 & 1.03 \\
\hline Plane 2-3 & C8 & 0.89 & 1.07 & 0.48 & 5.89 & 1.24 & 1.18 & 17.83 & 0.53 & 1.56 \\
\hline Plane 1-3 & & & 1.07 & 0.66 & & 1.02 & 0.47 & & 0.76 & 0.53 \\
\hline Plane 1-2 & & & 0.99 & 0.20 & & 1.01 & 1.66 & & 0.92 & 1.51 \\
\hline Plane 2-3 & C2' & 2.67 & 0.99 & 0.84 & 6.08 & 1.24 & 1.34 & 6.65 & 0.65 & 0.07 \\
\hline Plane 1-3 & & & 0.99 & 1.04 & & 1.01 & 0.32 & & 0.92 & 1.58 \\
\hline
\end{tabular}

Table S4: Analysis of variance for chemical shifts distinguishing G-tetrad planes. F-value provided for each dataset is shaded in green and red for probability $<$ and $\geq 0.05$, respectively. Values where least significant difference (LSD) is lesser/greater than absolute mean difference (AMD) are shaded in green/red. 
Methods: Details of comparing performance of machine learning protocols.

Comparison of various machine learning protocols was performed using sklearn (.ensemble.RandomForestClassifier, .linear_model.LogisticRegression, .naive_bayes.GaussinNB, .model_selection.LinearDiscriminantAnalysis, .tree.DecisionTreeClassifier, .neighbors.KNneighborsClass-ifier, .svm.SVC) with cross-validation performed (sklearn.model_selection.cv) and plotted using seaborn library in python (version 3.7.4) employing all ${ }^{1} \mathrm{H}$ resonances (i.e. H1, H8, H1', H2', H2"). Model comparison is shown in Figure S7. Datasets used for:

Parallel: $\quad$ 1XAV, 2KYP, 2LD8, 2LEE, 2LK7, 2LPW, 2LXQ, 2M27, 2M4P, 2M92, 2M93, 2MB2, 2N4Y, 5I2V, 5NYS, 6NEB, 6T2G, $\mathrm{GGG}^{\mathrm{A}}\left(\mathrm{K}^{+}\right)$

Hybrid (anti): 186D, 2F8U, 2GKU, 2JSL, 2JSM, 2LOD, 5MTA

Hybrid (syn): 186D, 2F8U, 2GKU, 2HY9, 2JPZ, 2JSL, 2JSM, 2LOD, 5MTA
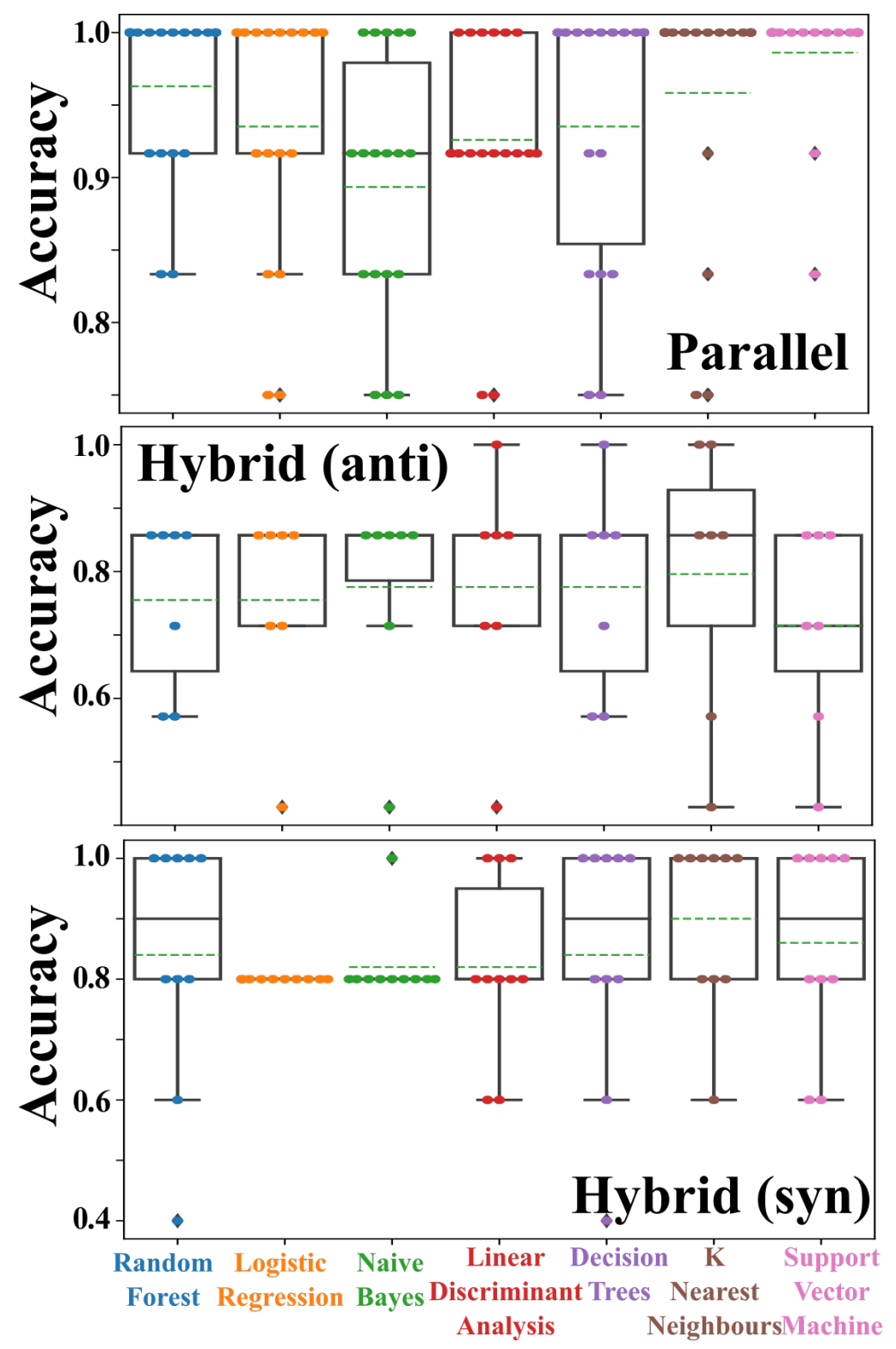

Figure S6: Performance of machine learning modelling protocols towards predicting G-tetrad pseudo plane information for parallel 12:0 (16 datasets), hybrid anti (7 datasets) and hybrid syn (9 datasets). 
Methods: Details of SVM protocol implemented for parallel and hybrid topologies

Machine learning algorithm for predicting G-tetrad plane from chemical shifts was formulated using Python (Version 3.7.4). The program uses pandas software library for importing data from an spreadsheet file, segregated across the parallel and hybrid topologies. Data for G-quadruplexes with modifications and/or ligands were removed from the analysis as the perturbations from canonical guanosine moiety or the effect of ring currents would interfere with effective interpretation of G-quadruplex structure. Further data analysis (handling of missing values, extracting the required data from array and randomization) was performed on the pandas DataFrame object. Python's numpy scientific computing library was used for handling multi-dimensional array output and splitting data frame into arrays. Matplotlib in conjunction with seaborn libraries were used for data visualization and plotting statistical graphics such as swarm plots, pairplots, histograms and heatmap matrices. Some pre-processing libraries of scikit-learn(sklearn) like StandardScaler were used for scaling the data with mean and standard deviation of the training dataset. The support vector machine mode ${ }^{37}$ used for computing decision boundaries was also imported from sklearn library. The classes for SVM were defined as the plane indices (i.e. P1, P2, P3, see Figure S1) and as three classes are present, multi-class SVM approach was performed. The modules train_test_split and GridSearchCV were imported from sklearn.model_selection for splitting the data into training and testing sets and doing a grid search to obtain best hyperparameters (C and gamma) for SVM model respectively.

Parallel topology: Datasets with 12:0 anti:syn ratio were used (see Table S4) from structures. Anti:syn ratios 8:4 (2L88) and 11:1 (2M90, 2N6C, 2MGN, 6SUU) were not included due to dearth of data and for effective training of SVM. All data acquired at $298 \mathrm{~K}$ were used, while data at different temperatures were excluded. In total, 18 datasets (Table S4) were used for training and prediction, with each dataset containing $\mathrm{H} 8, \mathrm{H} 1$ ', $\mathrm{H} 2$ ' and $\mathrm{H} 2$ " shifts for 12 of the guanosine nucleotides that form the tetrad within a given G-quadruplex. The program was written to choose one of the 18 datasets for prediction, with 14 out of the 17 remaining structures randomly chosen for SVM training. This exercise was repeated 1000 times for each dataset in order to assess the prediction reliability. For each dataset predicted, the outcome was adjudged with "true positive" (TP) predictions where a correct prediction for a nucleotide is obtained by more than 500 times. This procedure was then iterated across all the 18 structures. The linear multi-class SVM model sufficed such that optimization of the "c" hyperparameter ensured successful prediction (Figure S8A). The optimized set-up ( $c=1.0$ ) was then used to predict the plane features for $\mathrm{GGG}^{\mathrm{TT}}$ sample in potassium buffer conditions (Table S4). The NOESY cross-peak assignment across the predicted resonances aided in quick and reliable sequential assignment (Figure S9). 
Hybrid topology: Datasets with 7:5 anti:syn ratio were used (see Table S4) from structures. Anti:syn ratios 9:3 (5ZEV) and 8:4 (5O4D, 2KPR, 6H1K) were not included due to dearth of data and for effective training of SVM. In this analysis, anti and syn bases were analysed individually in order to ensure effectively extract structural parameters apart from glycosidic torsion angle. In total, 7 and 9 datasets were available for anti and syn bases across samples with each dataset containing H8, H1', H2' and H2" shifts for 12 of the guanosine nucleotides that form the tetrad within a given G-quadruplex. The program was written to choose one of the 7 (9) datasets for anti (syn) prediction, with 5 (6) out of the 7 (9) remaining structures randomly chosen for SVM training. The procedure was repeated as described for parallel topology (although less number of random combinations are possible in this case due to relatively less amount of data). Optimization of the linear multi-class SVM for anti and syn bases is shown in Figure S8A. Radial basis function (RBF) multi-class SVM was also performed with optimization performed for "c" and "gamma" hyperparameters to check for better prediction. The heat-map for the two-dimensional grid search for optimized parameters is provided in Figures S8B and S8C. The optimized set-up was then used to predict the plane features for GGG $^{\mathrm{TT}}$ sample in sodium buffer conditions (Table S4).
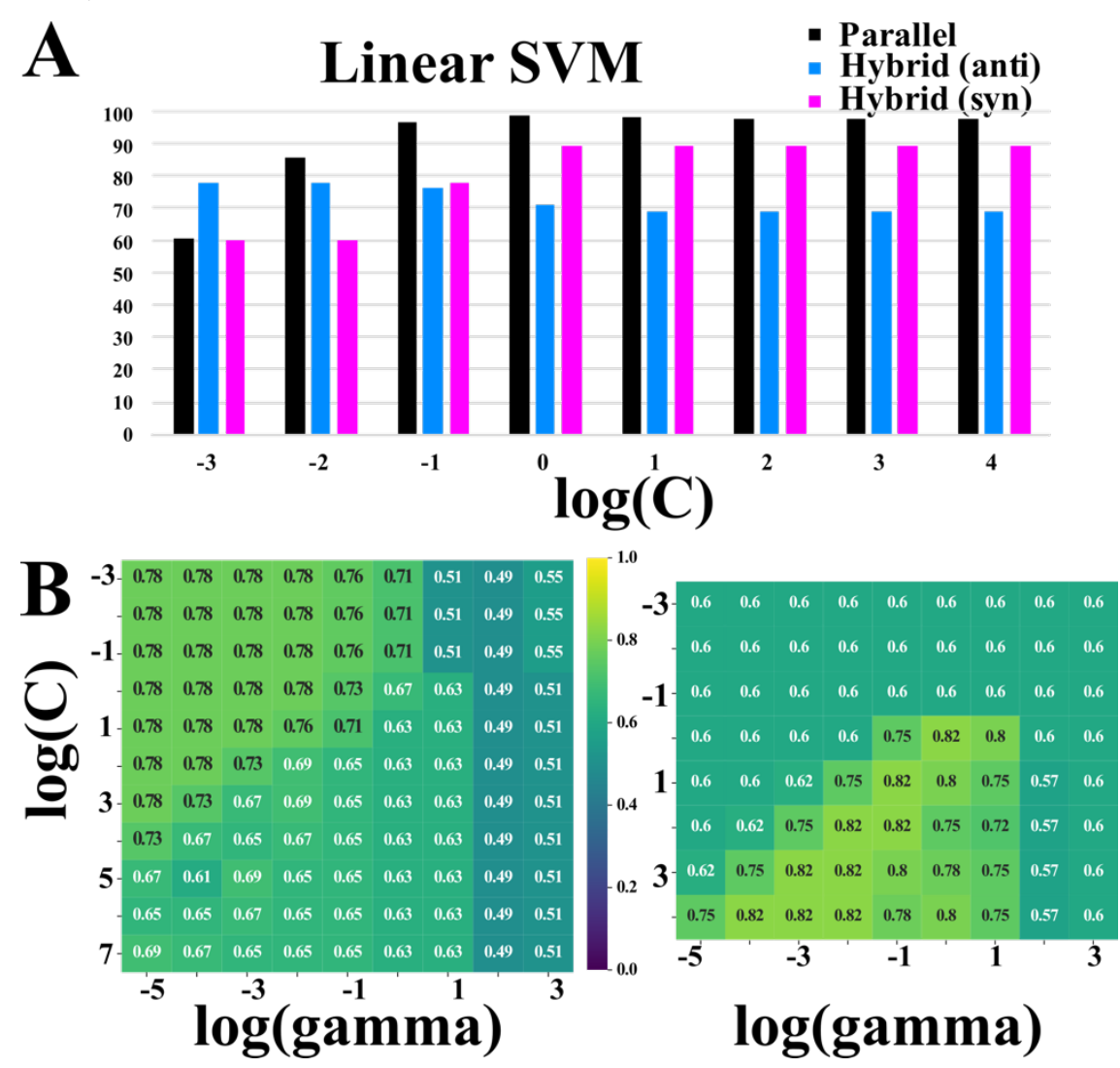

Figure S7: Benchmarking and performance of SVM towards prediction of SVM. (A) Linear SVM performance as a function of hyperparameter "c". (B) RBF SVM performance as a function of hyperparameters "c" and "gamma" for hybrid anti (left) and syn (right). 


\begin{tabular}{|c|c|c|c|}
\hline Parallel & \multicolumn{3}{|c|}{ Anti bases (c= 1) } \\
\hline PDB ID & Plane 1 & Plane 2 & Plane 3 \\
\hline 1XAV & 4 & 4 & 4 \\
\hline 2KYP & 4 & 4 & 4 \\
\hline 2LD8 & 4 & 3 & $4(1)$ \\
\hline 2LEE & 4 & 4 & 4 \\
\hline 2LK7 & 4 & 4 & 4 \\
\hline 2LPW & 4 & 4 & 4 \\
\hline 2LXQ & 4 & 4 & 4 \\
\hline 2M27 & 4 & 4 & 4 \\
\hline 2M4P & 4 & 4 & 4 \\
\hline 2M92 & 4 & 4 & 4 \\
\hline 2M93 & 4 & 4 & 4 \\
\hline 2MB2 & 4 & 4 & 4 \\
\hline 2N4Y & 4 & 4 & 4 \\
\hline 5I2V & $4(1)$ & $3(1)$ & 3 \\
\hline 5NYS & 4 & 4 & 4 \\
\hline 6NEB & 4 & 4 & 4 \\
\hline 6T2G & 4 & 4 & 4 \\
\hline GGG $^{\mathrm{M}}$ & 4 & 4 & 4 \\
\hline GGG $^{\mathrm{T}}\left(\mathrm{K}^{+}\right)$ & 4 & 4 & 4 \\
\hline
\end{tabular}

\begin{tabular}{|c|c|c|c|c|c|c|}
\hline Hybrid & \multicolumn{2}{|c|}{ Syn bases (Linear SVM, c=E0) } & \multicolumn{3}{c|}{ Anti bases (Linear SVM, c=E-3) } \\
\hline PDB ID & Plane 1 & Plane 2 & Plane 3 & Plane 1 & Plane 2 & Plane 3 \\
\hline 186D & $3(1)$ & 1 & 0 & 0 & $1(2)$ & $2(2)$ \\
\hline 2F8U & 2 & 1 & $1(1)$ & 0 & $3(1)$ & 3 \\
\hline 2GKU & $3(1)$ & 1 & 0 & 0 & 3 & $3(1)$ \\
\hline 2HY9 & $3(1)$ & 1 & 0 & - & - & - \\
\hline 2JPZ & 3 & 1 & 1 & - & - & - \\
\hline 2JSL & 3 & 1 & 1 & 0 & $3(1)$ & 3 \\
\hline 2JSM & 3 & 1 & 1 & 0 & $3(1)$ & $2(1)$ \\
\hline 2LOD & $3(1)$ & 1 & 0 & 0 & 3 & $3(1)$ \\
\hline 5MTA & 3 & 1 & 1 & 0 & $3(1)$ & 3 \\
\hline $\mathrm{GGG}^{\mathrm{TT}}\left(\mathrm{Na}^{+}\right)$ & $2(1)$ & 1 & $0(1)$ & 0 & $1(2)$ & $2(2)$ \\
\hline
\end{tabular}

\begin{tabular}{|c|c|c|c|c|c|c|}
\hline Hybrid & \multicolumn{2}{|c|}{ Syn (RBF SVM, c=E1, gamma = E-2) } & \multicolumn{2}{c|}{ Anti (RBF SVM c=10, gamma = E-5) } \\
\hline PDB ID & Plane 1 & Plane 2 & Plane 3 & Plane 1 & Plane 2 & Plane 3 \\
\hline 186D & $3(1)$ & 1 & 0 & 0 & $1(2)$ & $2(2)$ \\
\hline 2F8U & $3(1)$ & 1 & 0 & 0 & $3(1)$ & 3 \\
\hline 2GKU & $3(1)$ & 1 & 0 & 0 & 3 & $3(1)$ \\
\hline 2HY9 & $3(1)$ & 1 & 0 & - & - & - \\
\hline 2JPZ & $3(1)$ & 1 & 0 & - & - & - \\
\hline 2JSL & $3(1)$ & 1 & 0 & 0 & $3(1)$ & 3 \\
\hline 2JSM & $3(1)$ & 1 & 0 & 0 & $3(1)$ & $2(1)$ \\
\hline 2LOD & $3(1)$ & 1 & 0 & 0 & 3 & $3(1)$ \\
\hline 5MTA & $3(1)$ & 1 & 0 & 0 & $3(1)$ & 3 \\
\hline $\mathrm{GGG}^{\mathrm{TT}}\left(\mathrm{Na}^{+}\right)$ & $3(1)$ & 1 & 0 & 0 & $1(2)$ & $2(2)$ \\
\hline
\end{tabular}

Table S5: Details of success of prediction for structural parameters using ${ }^{1} \mathrm{H}$ chemical shifts. True positive values predicted are provided for each structure, with false positive numbers in parenthesis. 


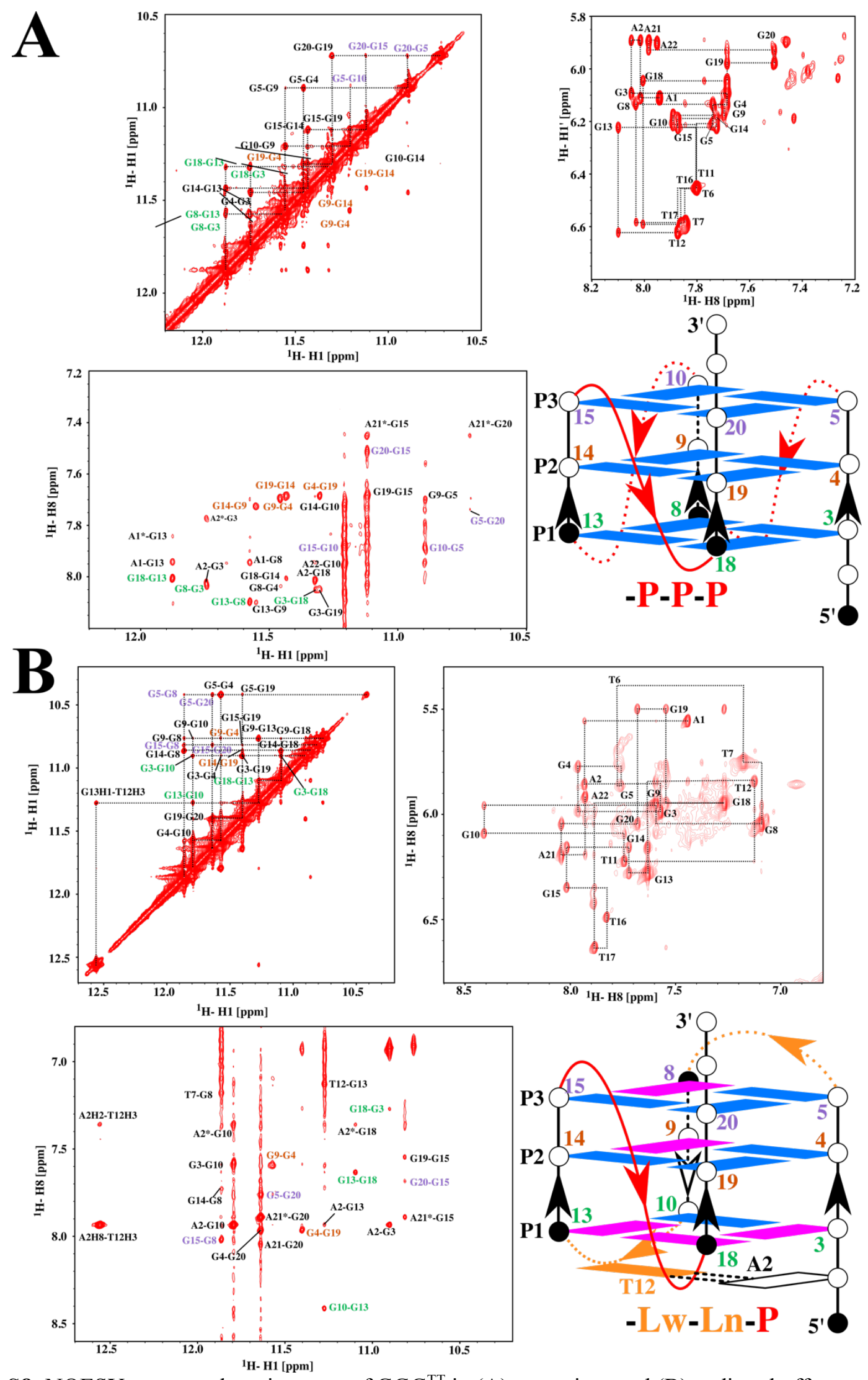

Figure S8: NOESY cross-peak assignment of $\mathrm{GGG}^{\mathrm{TT}}$ in (A) potassium and (B) sodium buffer conditions. 
Table S6: Chemical shifts tables (values referenced with TSP at $0.00 \mathrm{ppm}, \mathrm{NaN}$ values indicate data that was not available due to exchange broadening, lower sensitivity or lack of data)

\begin{tabular}{|c|c|c|c|c|c|c|c|c|c|c|c|}
\hline \multicolumn{12}{|c|}{ GGG $^{\text {T }}$} \\
\hline POSITION & G(anti) / G(syn) & PLANE & C8 & H8 & C1' & H1' & C2' & H2' & H2" & N1 & H1 \\
\hline G3 & anti & 1 & 137.9 & 8.06 & 84.5 & 6.10 & 39.8 & 2.81 & 3.01 & 144.1 & 11.86 \\
\hline G4 & anti & 2 & 137.1 & 7.65 & 84.5 & 6.18 & 42.6 & 2.60 & 2.92 & 142.8 & 11.37 \\
\hline G5 & anti & 3 & 138.0 & 7.77 & 85.4 & 6.46 & 41.8 & 2.62 & 2.74 & 144.5 & 11.18 \\
\hline G7 & anti & 1 & 137.4 & 7.97 & 87.2 & 6.11 & 44.0 & 2.44 & 2.93 & 143.8 & 11.46 \\
\hline G8 & anti & 2 & 138.3 & 7.94 & 84.2 & 6.22 & 43.1 & 2.67 & 2.95 & 142.9 & 11.42 \\
\hline G9 & anti & 3 & 138.3 & 7.86 & 85.3 & 6.49 & 41.6 & 2.62 & 2.73 & 144.6 & 11.40 \\
\hline G11 & anti & 1 & 138.0 & 8.08 & 87.1 & 6.24 & 44.0 & 2.55 & 3.01 & 144.3 & 11.83 \\
\hline G12 & anti & 2 & 138.2 & 7.98 & 84.1 & 6.23 & 43.0 & 2.70 & 2.95 & 142.8 & 11.31 \\
\hline G13 & anti & 3 & 138.0 & 7.83 & 85.3 & 6.48 & 41.7 & 2.62 & 2.73 & 144.5 & 11.22 \\
\hline G15 & anti & 1 & 137.7 & 7.96 & 87.2 & 6.04 & 44.2 & 2.36 & 2.81 & 143.7 & 11.29 \\
\hline G16 & anti & 2 & 138.2 & 7.96 & 84.0 & 6.00 & 42.5 & 2.68 & 2.76 & 143.4 & 11.34 \\
\hline G17 & anti & 3 & 136.8 & 7.50 & 84.5 & 5.93 & 41.2 & 2.37 & 2.69 & 144.4 & 10.83 \\
\hline \multicolumn{12}{|c|}{ GGG $^{\mathbf{A}}$} \\
\hline POSITION & G(anti) / G(syn) & PLANE & C8 & H8 & C1' & H1' & C2' & H2' & H2" & N1 & H1 \\
\hline G3 & anti & 1 & 137.8 & 8.07 & 84.5 & 6.11 & 39.7 & 2.82 & 3.02 & 144.1 & 11.88 \\
\hline G4 & anti & 2 & 137.2 & 7.66 & 84.4 & 6.20 & 42.6 & 2.60 & 2.93 & 142.8 & 11.38 \\
\hline G5 & anti & 3 & 137.9 & 7.77 & 85.3 & 6.47 & 41.5 & 2.63 & 2.75 & 144.5 & 11.20 \\
\hline G7 & anti & 1 & 137.3 & 7.99 & 87.2 & 6.12 & 43.9 & 2.46 & 2.95 & 143.8 & 11.46 \\
\hline G8 & anti & 2 & 138.2 & 7.94 & 84.3 & 6.24 & 43.0 & 2.68 & 2.96 & 143.0 & 11.44 \\
\hline G9 & anti & 3 & 138.2 & 7.87 & 85.2 & 6.51 & 41.7 & 2.62 & 2.74 & 144.6 & 11.42 \\
\hline G11 & anti & 1 & 138.0 & 8.09 & 87.1 & 6.25 & 44.0 & 2.57 & 3.03 & 144.4 & 11.84 \\
\hline G12 & anti & 2 & 138.2 & 7.98 & 84.1 & 6.25 & 42.9 & 2.70 & 2.98 & 142.8 & 11.32 \\
\hline G13 & anti & 3 & 138.0 & 7.83 & 85.2 & 6.49 & 41.7 & 2.63 & 2.74 & 144.4 & 11.24 \\
\hline G15 & anti & 1 & 137.7 & 7.98 & 87.2 & 6.05 & 44.2 & 2.38 & 2.82 & 143.7 & 11.29 \\
\hline G16 & anti & 2 & 138.2 & 7.96 & 84.0 & 6.00 & 42.5 & 2.68 & 2.76 & 143.5 & 11.34 \\
\hline G17 & anti & 3 & 136.8 & 7.50 & 84.4 & 5.92 & 41.1 & 2.37 & 2.69 & 144.4 & 10.84 \\
\hline \multicolumn{12}{|c|}{ GGG $^{\text {TT }}(\mathbf{K}+)$} \\
\hline POSITION & G(anti) / G(syn) & PLANE & C8 & H8 & C1' & H1' & C2' & H2' & H2" & N1 & H1 \\
\hline G3 & anti & 1 & 137.9 & 8.05 & 84.4 & 6.09 & 40.2 & 2.77 & 3.02 & 144.0 & 11.74 \\
\hline G4 & anti & 2 & 137.3 & 7.69 & 84.2 & 6.14 & 42.4 & 2.61 & 2.79 & 143.2 & 11.46 \\
\hline G5 & anti & 3 & 137.6 & 7.74 & 84.6 & 6.21 & 42.4 & 2.54 & 2.77 & 143.8 & 10.89 \\
\hline G8 & anti & 1 & 137.7 & 8.03 & 85.4 & 6.14 & 42.4 & 2.50 & 2.93 & 143.9 & 11.58 \\
\hline G9 & anti & 2 & 137.6 & 7.70 & 84.1 & 6.18 & 42.4 & 2.66 & 2.81 & 144.3 & 11.55 \\
\hline G10 & anti & 3 & 137.9 & 7.89 & 84.6 & 6.21 & 42.4 & 2.51 & 2.76 & 144.1 & 11.21 \\
\hline G13 & anti & 1 & 138.2 & 8.10 & 85.2 & 6.22 & 42.3 & 2.59 & 2.98 & 144.4 & 11.88 \\
\hline G14 & anti & 2 & 137.5 & 7.73 & 84.1 & 6.19 & 42.3 & 2.70 & 2.85 & 143.3 & 11.43 \\
\hline G15 & anti & 3 & 137.9 & 7.87 & 84.6 & 6.22 & 42.4 & 2.51 & 2.75 & 144.1 & 11.12 \\
\hline G18 & anti & 1 & 138.0 & 8.01 & 85.4 & 6.05 & 42.6 & 2.46 & 2.81 & $\begin{array}{l}143.8 \\
\end{array}$ & 11.32 \\
\hline G19 & anti & 2 & 137.3 & 7.68 & 84.1 & 5.98 & 42.1 & 2.65 & 2.75 & 143.3 & 11.30 \\
\hline G20 & anti & 3 & 136.9 & 7.51 & 84.0 & 5.93 & 40.7 & 2.38 & 2.65 & 143.9 & 10.72 \\
\hline
\end{tabular}




\begin{tabular}{|c|c|c|c|c|c|c|c|c|c|c|c|}
\hline \multicolumn{12}{|c|}{ GGG $^{A T}(K+)$} \\
\hline POSITION & G(anti) / G(syn) & PLANE & C8 & H8 & C1' $^{\prime}$ & H1' & $\mathrm{C2}^{\prime}$ & H2' & H2" & N1 & H1 \\
\hline G3 & anti & 1 & 137.9 & 8.06 & 84.4 & 6.12 & 40.0 & 2.78 & 3.04 & 144.1 & 11.77 \\
\hline G4 & anti & 2 & 137.3 & 7.70 & 84.3 & 6.12 & 42.4 & 2.62 & 2.75 & 143.3 & 11.49 \\
\hline G5 & anti & 3 & 137.6 & 7.67 & 84.4 & 6.15 & 42.4 & 2.50 & 2.65 & 143.8 & 10.96 \\
\hline G8 & anti & 1 & 137.5 & 7.89 & 85.6 & 6.11 & 42.3 & 2.32 & 2.93 & 144.0 & 11.56 \\
\hline G9 & anti & 2 & 137.9 & 7.83 & 84.2 & 6.18 & 42.2 & 2.76 & 2.80 & 143.4 & 11.57 \\
\hline G10 & anti & 3 & 137.7 & 7.84 & 84.4 & 6.16 & 42.3 & 2.46 & 2.67 & 144.2 & 11.27 \\
\hline G13 & anti & 1 & 138.1 & 8.00 & 85.4 & 6.21 & 42.3 & 2.46 & 2.98 & 144.5 & 11.87 \\
\hline G14 & anti & 2 & 137.9 & 7.84 & 84.2 & 6.19 & 42.2 & 2.77 & 2.82 & 143.3 & 11.48 \\
\hline G15 & anti & 3 & 137.6 & 7.82 & 84.3 & 6.17 & 42.4 & 2.48 & 2.66 & 144.1 & 11.16 \\
\hline G18 & anti & 1 & 137.9 & 7.90 & 85.6 & 6.01 & 42.5 & 2.35 & 2.81 & 143.9 & 11.35 \\
\hline G19 & anti & 2 & 137.8 & 7.81 & 84.2 & 6.01 & 42.0 & 2.73 & 2.78 & 143.4 & 11.30 \\
\hline G20 & anti & 3 & 136.8 & 7.51 & 83.9 & 5.92 & 40.5 & 2.39 & 2.65 & 144.0 & 10.79 \\
\hline \multicolumn{12}{|c|}{ 1XAV } \\
\hline POSITION & G(anti) / G(syn) & PLANE & $\mathrm{C8}$ & H8 & C1' & H1' & C2' & $\mathbf{H}^{\prime}$ & H2" & N1 & H1 \\
\hline G4 & anti & 1 & 138.0 & 8.04 & 84.6 & 6.07 & 40.2 & 2.77 & 3.02 & $\mathrm{NaN}$ & 11.75 \\
\hline G5 & anti & 2 & 137.3 & 7.75 & 84.3 & 6.14 & 42.4 & 2.63 & 2.91 & $\mathrm{NaN}$ & 11.23 \\
\hline G6 & anti & 3 & 137.8 & 7.77 & 85.1 & 6.43 & 41.4 & 2.61 & 2.80 & $\mathrm{NaN}$ & 10.59 \\
\hline G8 & anti & 1 & 137.9 & 8.00 & 87.2 & 6.16 & 43.9 & 2.48 & 2.93 & $\mathrm{NaN}$ & 11.71 \\
\hline G9 & anti & 2 & 137.7 & 7.92 & 84.1 & 6.15 & 42.8 & 2.68 & 2.86 & $\mathrm{NaN}$ & 11.50 \\
\hline G10 & anti & 3 & 137.8 & 7.88 & 85.0 & 6.45 & 41.4 & 2.61 & 2.78 & $\mathrm{NaN}$ & 11.06 \\
\hline G13 & anti & 1 & 138.4 & 8.13 & 85.7 & 6.18 & 42.2 & 2.65 & 2.98 & $\mathrm{NaN}$ & 11.91 \\
\hline G14 & anti & 2 & 137.6 & 7.82 & 84.5 & 6.21 & 42.6 & 2.71 & 2.98 & $\mathrm{NaN}$ & 11.26 \\
\hline G15 & anti & 3 & 137.6 & 7.82 & 85.1 & 6.47 & 42.4 & 2.64 & 2.74 & $\mathrm{NaN}$ & 11.05 \\
\hline G17 & anti & 1 & 138.1 & 7.92 & 87.1 & 6.00 & 44.1 & 2.36 & 2.81 & $\mathrm{NaN}$ & 11.28 \\
\hline G18 & anti & 2 & 138.2 & 7.92 & 83.9 & 6.05 & 41.5 & 2.69 & 2.74 & $\mathrm{NaN}$ & 11.35 \\
\hline G19 & anti & 3 & 136.9 & 7.63 & 84.8 & 6.18 & 41.1 & 2.6 & 2.8 & $\mathrm{NaN}$ & 11.05 \\
\hline \multicolumn{12}{|c|}{ 2LOD } \\
\hline POSITION & G(anti) / G(syn) & PLANE & $\mathrm{C8}$ & H8 & C1' & H1' & C2' & $\mathbf{H 2}^{\prime}$ & H2" & N1 & H1 \\
\hline G1 & syn & 1 & 141.6 & 7.58 & 90.2 & 6.22 & 39.5 & 2.74 & 3.28 & 144.1 & 11.65 \\
\hline G2 & anti & 2 & 138.2 & 7.96 & 83.6 & 6.01 & 42.7 & 2.55 & 2.73 & 144.5 & 11.63 \\
\hline G3 & anti & 3 & 137.3 & 7.62 & 84.7 & 6.26 & 42.1 & 2.65 & 2.74 & 144.7 & 11.06 \\
\hline G6 & syn & 1 & 141.7 & 7.25 & 89.4 & 6.00 & 35.2 & 2.96 & 3.08 & 143.9 & 11.61 \\
\hline G7 & anti & 2 & 138.4 & 7.84 & 83.3 & 5.77 & 42.0 & 2.63 & 2.63 & 143.8 & 11.61 \\
\hline G8 & anti & 3 & 136.7 & 7.52 & 84.4 & 5.94 & 41.1 & 2.11 & 2.43 & 144.7 & 11.11 \\
\hline G14 & syn & 3 & 141.7 & 7.26 & 88.8 & 6.05 & 36.4 & 3.06 & 3.49 & 143.7 & 11.08 \\
\hline G15 & syn & 2 & 140.8 & 7.38 & 88.3 & 5.79 & 38.5 & 2.54 & 2.54 & 142.4 & 11.38 \\
\hline G16 & anti & 1 & 137.7 & 7.67 & 83.7 & 5.95 & 41.2 & 2.54 & 2.57 & 144.6 & 11.62 \\
\hline G20 & syn & 1 & 142.2 & 7.42 & 89.2 & 6.02 & 35.1 & 2.97 & 3.58 & 144.5 & 11.82 \\
\hline G21 & anti & 2 & 138.5 & 7.93 & 83.8 & 5.81 & 42.4 & 2.52 & 2.71 & $\mathrm{NaN}$ & 11.93 \\
\hline G22 & anti & 3 & 137.5 & 7.75 & 84.8 & 6.28 & 43.0 & 2.37 & 2.50 & 144.1 & 11.25 \\
\hline
\end{tabular}




\begin{tabular}{|c|c|c|c|c|c|c|c|c|c|c|c|}
\hline \multicolumn{12}{|c|}{ 2JSM } \\
\hline POSITION & G(anti) / G(syn) & PLANE & C8 & H8 & C1' & H1' & $\mathbf{C 2}^{\prime}$ & H2' & H2" & N1 & H1 \\
\hline G3 & syn & 1 & 141.6 & 7.29 & 89.4 & 5.99 & 35.3 & 2.97 & 3.45 & 144.8 & 11.78 \\
\hline G4 & anti & 2 & 138.5 & 8.00 & 83.5 & 5.80 & 42.1 & 2.60 & 2.69 & 143.6 & 11.66 \\
\hline G5 & anti & 3 & 137.8 & 7.91 & 85.1 & 6.36 & 43.1 & 2.53 & 2.60 & 145.4 & 11.10 \\
\hline G9 & syn & 1 & 141.8 & 7.41 & 89.2 & 5.99 & 34.3 & 3.07 & 3.49 & 144.5 & 11.92 \\
\hline G10 & anti & 2 & 138.5 & 7.97 & 83.6 & 5.76 & 42.2 & 2.54 & 2.63 & 144.2 & 11.91 \\
\hline G11 & anti & 3 & 137.3 & 7.92 & 84.5 & 6.16 & 40.5 & 2.59 & 2.82 & 144.6 & 11.65 \\
\hline G15 & syn & 3 & 141.3 & 7.33 & 89.1 & 6.09 & 35.2 & 3.17 & 3.70 & 142.5 & 10.81 \\
\hline G16 & syn & 2 & 140.7 & 7.37 & 88.2 & 5.74 & 38.5 & 2.46 & 2.46 & 142.3 & 11.06 \\
\hline G17 & anti & 1 & 137.4 & 7.43 & 83.7 & 5.90 & 41.5 & 2.61 & 2.63 & 144.5 & 11.61 \\
\hline G21 & syn & 1 & 141.1 & 7.06 & 89.1 & 5.91 & 35.3 & 2.96 & 3.47 & 144.6 & 11.37 \\
\hline G22 & anti & 2 & 137.3 & 7.72 & 84.0 & 5.87 & 42.6 & 2.54 & 2.70 & 143.6 & 11.54 \\
\hline G23 & anti & 3 & 137.7 & 7.72 & 84.9 & 6.32 & 43.3 & 2.51 & 2.57 & 144.2 & 10.80 \\
\hline \multicolumn{12}{|c|}{ 2GKU } \\
\hline POSITION & G(anti) / G(syn) & PLANE & $\mathrm{C8}$ & H8 & C1' & H1' & C2' & $\mathrm{H}^{\prime}$ & H2" & N1 & H1 \\
\hline G3 & syn & 1 & 141.6 & 7.44 & 89.6 & 6.09 & 35.6 & 2.96 & 3.39 & 144.9 & 12.04 \\
\hline G4 & anti & 2 & 138.6 & 7.97 & 83.4 & 5.79 & 42.1 & 2.57 & 2.64 & 143.8 & 11.77 \\
\hline G5 & anti & 3 & 137.3 & 7.82 & 85.2 & 6.40 & 43.4 & 2.61 & 2.61 & 144.9 & 11.06 \\
\hline G9 & syn & 1 & 141.6 & 7.34 & 89.3 & 5.95 & 34.1 & 3.00 & 3.43 & 144.5 & 11.88 \\
\hline G10 & anti & 2 & 138.8 & 8.04 & 83.3 & 5.66 & 41.6 & 2.64 & 2.64 & 144.7 & 12.19 \\
\hline G11 & anti & 3 & 137.2 & 7.95 & 84.3 & 6.29 & 42.1 & 2.55 & 2.68 & 144.6 & 11.28 \\
\hline G15 & syn & 3 & 141.6 & 7.35 & 88.4 & 6.11 & 36.6 & 2.99 & 3.50 & 144.8 & 11.34 \\
\hline G16 & syn & 2 & 140.2 & 7.32 & 88.4 & 5.76 & 38.2 & 2.47 & 2.54 & 142.8 & 11.22 \\
\hline G17 & anti & 1 & 137.7 & 7.67 & 83.7 & 5.95 & 41.2 & 2.61 & 2.67 & 144.9 & 11.80 \\
\hline G21 & syn & 1 & 142.0 & 7.36 & 89.5 & 6.05 & 35.8 & 2.97 & 3.48 & 145.0 & 11.47 \\
\hline G22 & anti & 2 & 138.0 & 8.07 & 83.3 & 5.79 & 41.7 & 2.69 & 2.69 & 143.8 & 11.66 \\
\hline G23 & anti & 3 & 136.5 & 7.43 & 84.9 & 5.90 & 41.9 & 2.16 & 2.55 & 144.4 & 10.67 \\
\hline \multicolumn{12}{|c|}{ GGG $^{\mathrm{AT}}(\mathrm{Na}+)$} \\
\hline POSITION & G(anti) / G(syn) & PLANE & $\mathrm{C8}$ & H8 & C1' & H1' & C2' & $\begin{array}{l}\mathbf{H}^{\prime} \\
\end{array}$ & H2" & N1 & H1 \\
\hline G3 & syn & 1 & 142.0 & 7.57 & 89.9 & 5.98 & $\mathrm{NaN}$ & 2.98 & 3.34 & 143.8 & 10.93 \\
\hline G4 & anti & 2 & 139.3 & 7.94 & 83.6 & 5.70 & $\mathrm{NaN}$ & 2.42 & 2.73 & 144.5 & 11.52 \\
\hline G5 & anti & 3 & 138.3 & 7.71 & 83.8 & 5.78 & $\mathrm{NaN}$ & 2.30 & 2.51 & 142.6 & 10.38 \\
\hline G8 & syn & 3 & 142.5 & 7.07 & 89.1 & 6.03 & $\mathrm{NaN}$ & 3.03 & 3.54 & 145.2 & 12.07 \\
\hline G9 & syn & 2 & 141.4 & 7.57 & 89.2 & 5.96 & $\mathrm{NaN}$ & 2.52 & 2.82 & 143.2 & 10.74 \\
\hline G10 & anti & 1 & 139.0 & 8.41 & 83.6 & 6.20 & $\mathrm{NaN}$ & 2.58 & 3.12 & 144.6 & 11.79 \\
\hline G13 & syn & 1 & 142.3 & 7.63 & 89.2 & 6.27 & $\mathrm{NaN}$ & 3.10 & 3.64 & 143.4 & 11.31 \\
\hline G14 & anti & 2 & 137.7 & 7.77 & 84.7 & 6.17 & $\mathrm{NaN}$ & 2.33 & 2.78 & 143.3 & 10.97 \\
\hline G15 & anti & 3 & 139.3 & 7.98 & 85.4 & 6.26 & $\mathrm{NaN}$ & 2.63 & 2.68 & 145.1 & 10.99 \\
\hline G18 & syn & 1 & 141.7 & 7.31 & 89.2 & 5.98 & $\mathrm{NaN}$ & 2.86 & 3.03 & 143.5 & 11.12 \\
\hline G19 & anti & 2 & 138.2 & 7.65 & 83.6 & 5.58 & $\mathrm{NaN}$ & 2.38 & 2.47 & 144.4 & 11.47 \\
\hline G20 & anti & 3 & 138.5 & 7.77 & 84.5 & 6.03 & $\mathrm{NaN}$ & 2.39 & 2.59 & 145.9 & 11.58 \\
\hline
\end{tabular}




\begin{tabular}{|c|c|c|c|c|c|c|c|c|c|c|c|}
\hline \multicolumn{12}{|c|}{ GGG $^{\text {TT }}(\mathrm{Na}+)$} \\
\hline POSITION & G(anti) / G(syn) & PLANE & C8 & H8 & $\mathrm{C1}^{\prime}$ & H1' & $\mathrm{C2}^{\prime}$ & H2' & H2" & N1 & H1 \\
\hline G3 & syn & 1 & 142.1 & 7.57 & 90.0 & 5.99 & 35.0 & 2.72 & 3.34 & 143.7 & 10.90 \\
\hline G4 & anti & 2 & 139.3 & 7.96 & 83.6 & 5.77 & 39.1 & 2.45 & 2.82 & 144.7 & 11.57 \\
\hline G5 & anti & 3 & 138.3 & 7.76 & 84.0 & 5.87 & $\mathrm{NaN}$ & 2.54 & 2.70 & 142.3 & 10.42 \\
\hline G8 & syn & 3 & 142.5 & 7.09 & 89.0 & 6.05 & 35.9 & 2.99 & 3.46 & 145.8 & 11.86 \\
\hline G9 & syn & 2 & 141.6 & 7.59 & 89.1 & 5.96 & 37.2 & 2.54 & 2.86 & 143.3 & 10.76 \\
\hline G10 & anti & 1 & 138.9 & 8.41 & 83.5 & 6.09 & 41.6 & 2.50 & 3.11 & 144.7 & 11.79 \\
\hline G13 & syn & 1 & 142.3 & 7.63 & 89.3 & 6.28 & 35.5 & 3.09 & 3.66 & 143.2 & 11.27 \\
\hline G14 & anti & 2 & 137.6 & 7.72 & 84.8 & 6.16 & 43.4 & 2.31 & 2.78 & 143.3 & 10.86 \\
\hline G15 & anti & 3 & 139.1 & 8.02 & 85.4 & 6.35 & 43.1 & 2.65 & 2.78 & 145.0 & 10.82 \\
\hline G18 & syn & 1 & 141.6 & 7.27 & 89.1 & 5.95 & 34.9 & 2.82 & 3.05 & 143.5 & 11.10 \\
\hline G19 & anti & 2 & 138.0 & 7.55 & 83.6 & 5.50 & 41.5 & 2.33 & 2.38 & 144.3 & 11.40 \\
\hline G20 & anti & 3 & 138.0 & 7.68 & 84.4 & 6.04 & 39.3 & 2.42 & 2.73 & 145.2 & 11.64 \\
\hline \multicolumn{12}{|c|}{$2 \mathrm{F8U}$} \\
\hline POSITION & G(anti) / G(syn) & PLANE & $\mathrm{C8}$ & H8 & C1' & H1' & $\mathrm{C2}^{\prime}$ & H2' & H2" & N1 & H1 \\
\hline G1 & syn & 1 & 140.8 & 7.26 & 89.7 & 5.87 & 38.5 & 2.81 & 3.11 & $\mathrm{NaN}$ & 11.84 \\
\hline G2 & anti & 2 & 138.7 & 7.87 & 83.6 & 5.74 & 42.4 & 2.48 & 2.69 & $\mathrm{NaN}$ & 11.79 \\
\hline G3 & anti & 3 & 136.8 & 7.51 & 84.3 & 5.89 & 42.7 & 2.55 & 2.65 & $\mathrm{NaN}$ & 10.89 \\
\hline G7 & syn & 3 & 142.0 & 7.40 & 89.0 & 6.09 & 35.5 & 3.18 & 3.80 & $\mathrm{NaN}$ & 11.72 \\
\hline G8 & syn & 2 & 141.5 & 7.68 & 88.2 & 5.85 & 38.1 & 2.65 & 2.75 & $\mathrm{NaN}$ & 11.47 \\
\hline G9 & anti & 1 & 137.9 & 7.89 & 83.5 & 5.57 & 40.7 & 2.45 & 2.57 & $\mathrm{NaN}$ & 11.10 \\
\hline G17 & syn & 1 & 142.1 & 7.55 & 89.2 & 6.22 & 36.3 & 3.07 & 3.48 & $\mathrm{NaN}$ & 11.81 \\
\hline G18 & anti & 2 & 137.6 & 7.88 & 84.3 & 6.11 & 43.4 & 2.53 & 2.94 & $\mathrm{NaN}$ & 11.42 \\
\hline G19 & anti & 3 & 138.3 & 7.53 & 85.5 & 6.48 & 41.8 & 2.76 & 2.76 & $\mathrm{NaN}$ & 11.01 \\
\hline G21 & syn & 1 & $\mathrm{NaN}$ & 6.61 & $\mathrm{NaN}$ & 5.45 & 35.9 & 2.97 & 2.97 & $\mathrm{NaN}$ & 11.67 \\
\hline G22 & anti & 2 & 139.2 & 8.13 & 83.5 & 5.84 & 42.4 & 2.65 & 2.72 & $\mathrm{NaN}$ & 11.49 \\
\hline G23 & anti & 3 & 137.8 & 7.80 & 85.2 & 6.41 & 43.2 & 2.45 & 2.56 & $\mathrm{NaN}$ & 11.30 \\
\hline \multicolumn{12}{|c|}{ 6AC7 } \\
\hline POSITION & G(anti) / G(syn) & PLANE & $\mathrm{C8}$ & H8 & C1' & H1' & $\mathrm{C2}^{\prime}$ & $\mathbf{H 2}^{\prime}$ & H2" & N1 & H1 \\
\hline G3 & syn & 1 & 141.9 & 7.47 & 89.6 & 6.11 & 35.0 & 3.06 & 3.39 & 144.5 & 11.74 \\
\hline G4 & anti & 2 & 138.5 & 8.12 & 83.2 & 5.86 & 41.9 & 2.60 & 2.71 & 143.4 & 11.95 \\
\hline G5 & anti & 3 & 136.0 & 7.28 & 85.1 & 6.27 & 43.6 & 2.44 & 2.60 & 144.3 & 11.24 \\
\hline G9 & syn & 3 & 141.5 & 7.62 & 89.7 & 6.38 & 37.3 & $\mathrm{NaN}$ & 2.7 & 145.7 & 10.95 \\
\hline G11 & syn & 2 & 141.0 & 7.38 & 88.8 & 5.91 & 35.6 & 2.78 & 2.81 & 144.1 & 11.59 \\
\hline G12 & anti & 1 & 137.5 & 7.69 & 83.5 & 6.09 & 41.8 & 2.75 & 2.75 & 145.0 & 11.83 \\
\hline G15 & syn & 1 & 141.7 & 7.41 & 89.6 & 6.11 & $\mathrm{NaN}$ & 3.15 & 3.15 & 143.7 & 11.50 \\
\hline G16 & anti & 2 & 138.9 & 8.03 & 83.3 & 5.87 & 42.3 & 2.60 & 2.69 & 144.0 & 11.65 \\
\hline G17 & anti & 3 & 137.7 & 7.74 & 85.8 & 6.36 & $\mathrm{NaN}$ & $\mathrm{NaN}$ & $\mathrm{NaN}$ & 144.7 & 10.82 \\
\hline G21 & syn & 1 & 141.7 & 7.28 & 89.4 & 5.96 & 35.3 & 2.94 & 3.24 & 144.9 & 11.78 \\
\hline G22 & anti & 2 & 138.7 & 8.09 & 83.2 & 5.81 & 41.5 & 2.68 & 2.77 & 143.7 & 11.77 \\
\hline G23 & anti & 3 & 137.2 & 7.77 & 85.5 & 6.41 & 43.7 & 2.45 & 2.52 & 144.5 & 11.35 \\
\hline
\end{tabular}




\begin{tabular}{|c|c|c|c|c|c|c|c|c|c|c|c|}
\hline \multicolumn{12}{|c|}{ 186D } \\
\hline POSITION & G(anti) / G(syn) & PLANE & C8 & H8 & C1' & H1' & $\mathbf{C 2}^{\prime}$ & H2' & H2" & N1 & H1 \\
\hline G3 & syn & 1 & 142.0 & 7.26 & 89.3 & 5.90 & 34.5 & 2.80 & 3.45 & $\mathrm{NaN}$ & 11.92 \\
\hline G4 & anti & 2 & 139.4 & 8.15 & 83.6 & 5.80 & 40.1 & 2.59 & 2.74 & $\mathrm{NaN}$ & 12.17 \\
\hline G5 & anti & 3 & 138.2 & 7.85 & 83.9 & 5.77 & $\mathrm{NaN}$ & 2.43 & 2.59 & $\mathrm{NaN}$ & 11.33 \\
\hline G10 & syn & 3 & 141.2 & 7.15 & 89.5 & 6.02 & 36.0 & 3.12 & 3.49 & $\mathrm{NaN}$ & 11.23 \\
\hline G11 & syn & 2 & 141.6 & 7.53 & 88.3 & 5.89 & 36.9 & 2.62 & 2.92 & $\mathrm{NaN}$ & 11.11 \\
\hline G12 & anti & 1 & 138.7 & 8.15 & 84.1 & 5.94 & 40.6 & 2.56 & 2.74 & $\mathrm{NaN}$ & 11.10 \\
\hline G16 & syn & 1 & 142.4 & 7.64 & 88.4 & 6.08 & 36.2 & 3.02 & 3.39 & $\mathrm{NaN}$ & 11.15 \\
\hline G17 & anti & 2 & 136.9 & 7.49 & 85.0 & 5.96 & 43.4 & 2.28 & 2.58 & $\mathrm{NaN}$ & 10.96 \\
\hline G18 & anti & 3 & 138.1 & 7.69 & 84.8 & 6.11 & 42.5 & 2.68 & 2.68 & $\mathrm{NaN}$ & 10.88 \\
\hline G21 & syn & 1 & 140.8 & 7.17 & 89.2 & 5.96 & 35.8 & 2.74 & 3.04 & $\mathrm{NaN}$ & 11.49 \\
\hline G22 & anti & 2 & 137.4 & 7.39 & 83.9 & 5.84 & 43.0 & 2.40 & 2.58 & $\mathrm{NaN}$ & 11.29 \\
\hline G23 & anti & 3 & 138.2 & 7.95 & 84.9 & 6.21 & $\mathrm{NaN}$ & 2.64 & 2.69 & $\mathrm{NaN}$ & 11.47 \\
\hline \multicolumn{12}{|c|}{ 2JSL } \\
\hline POSITION & G(anti) / G(syn) & PLANE & $\mathrm{C8}$ & H8 & C1' & H1' & C2' & $\mathrm{H}^{\prime}$ & H2" & N1 & H1 \\
\hline G3 & syn & 1 & 141.9 & 7.41 & 89.3 & 6.03 & 35.2 & 3.00 & 3.47 & $\mathrm{NaN}$ & $\mathrm{NaN}$ \\
\hline G4 & anti & 2 & 138.7 & 7.94 & 83.8 & 5.78 & 42.1 & 2.48 & 2.72 & 143.6 & 11.80 \\
\hline G5 & anti & 3 & 137.6 & 7.82 & 84.2 & 6.01 & 42.2 & 2.32 & 2.40 & 143.8 & 10.93 \\
\hline G9 & syn & 3 & 141.9 & 7.37 & 89.3 & 6.11 & 35.4 & 3.24 & 3.79 & 143.9 & 11.23 \\
\hline G10 & syn & 2 & 141.1 & 7.45 & 88.1 & 5.82 & 38.5 & 2.50 & 2.66 & 141.9 & 11.18 \\
\hline G11 & anti & 1 & 138.0 & 7.93 & 83.7 & 5.96 & 41.1 & 2.47 & 2.63 & 144.7 & 11.63 \\
\hline G15 & syn & 1 & 141.3 & 7.03 & 88.9 & 5.91 & 35.9 & 2.97 & 3.42 & 143.7 & 11.17 \\
\hline G16 & anti & 2 & 138.4 & 7.68 & 84.1 & 5.88 & 42.8 & 2.41 & 2.73 & 143.1 & 11.51 \\
\hline G17 & anti & 3 & 137.4 & 7.68 & 84.9 & 6.26 & 43.6 & 2.57 & 2.64 & 143.5 & 10.62 \\
\hline G21 & syn & 1 & 141.4 & 7.23 & 89.2 & 5.96 & 34.8 & 2.97 & 3.26 & 144.4 & 11.66 \\
\hline G22 & anti & 2 & 138.4 & 7.97 & 83.5 & 5.84 & 42.2 & 2.62 & 2.71 & 143.1 & 11.46 \\
\hline G23 & anti & 3 & 137.9 & 7.83 & 85.1 & 6.21 & 41.6 & 2.53 & 2.80 & 143.9 & 11.35 \\
\hline \multicolumn{12}{|c|}{$2 \mathrm{JPZ}$} \\
\hline POSITION & G(anti) / G(syn) & PLANE & $\mathrm{C8}$ & H8 & C1' & H1' & C2' & $\begin{array}{l}\mathbf{H}^{\prime} \\
\end{array}$ & H2" & N1 & H1 \\
\hline G4 & syn & 1 & 141.9 & 7.42 & 89.3 & 6.03 & 35.2 & 2.99 & 3.46 & $\mathrm{NaN}$ & 11.62 \\
\hline G5 & anti & 2 & 138.8 & 7.97 & 83.8 & 5.78 & 42.0 & 2.51 & 2.71 & $\mathrm{NaN}$ & 11.81 \\
\hline G6 & anti & 3 & 137.6 & 7.82 & 84.2 & 6.02 & 42.2 & 2.32 & 2.40 & $\mathrm{NaN}$ & 10.92 \\
\hline G10 & syn & 3 & 141.8 & 7.35 & 89.3 & 6.10 & 35.4 & 3.22 & 3.77 & $\mathrm{NaN}$ & 11.21 \\
\hline G11 & syn & 2 & 141.1 & 7.41 & 88.1 & 5.80 & 38.4 & 2.49 & 2.63 & $\mathrm{NaN}$ & 11.14 \\
\hline G12 & anti & 1 & 137.9 & 7.85 & 83.7 & 5.94 & $\mathrm{NaN}$ & $\mathrm{NaN}$ & $\mathrm{NaN}$ & $\mathrm{NaN}$ & 11.62 \\
\hline G16 & syn & 1 & $\mathrm{NaN}$ & 7.13 & 89.1 & 5.97 & 35.9 & 2.99 & 3.44 & $\mathrm{NaN}$ & 11.21 \\
\hline G17 & anti & 2 & 137.5 & 7.70 & 84.1 & 5.90 & 42.8 & 2.43 & 2.75 & $\mathrm{NaN}$ & 11.52 \\
\hline G18 & anti & 3 & 138.3 & 7.69 & 84.9 & 6.27 & 43.6 & 2.58 & 2.64 & $\mathrm{NaN}$ & 10.63 \\
\hline G22 & syn & 1 & 141.3 & 7.13 & 89.2 & 5.92 & 34.9 & 2.96 & 3.24 & $\mathrm{NaN}$ & 11.65 \\
\hline G23 & anti & 2 & 138.4 & 7.97 & 83.4 & 5.82 & 42.2 & 2.62 & 2.70 & $\mathrm{NaN}$ & 11.44 \\
\hline G24 & anti & 3 & 137.8 & 7.81 & 85.1 & 6.21 & 41.6 & 2.53 & 2.80 & $\mathrm{NaN}$ & 11.33 \\
\hline
\end{tabular}




\begin{tabular}{|c|c|c|c|c|c|c|c|c|c|c|c|}
\hline \multicolumn{12}{|c|}{ 2KPR } \\
\hline POSITION & G(anti) / G(syn) & PLANE & C8 & H8 & C1' & H1' & $\mathbf{C 2}^{\prime}$ & H2' & H2" & N1 & H1 \\
\hline G1 & syn & 2 & 140.7 & 7.31 & 89.9 & 5.90 & 39.8 & 2.48 & 2.56 & 144.8 & 11.76 \\
\hline $\mathrm{G} 2$ & anti & 3 & 137.6 & 7.75 & 84.4 & 6.21 & 38.0 & 2.55 & 3.02 & 144.2 & 11.68 \\
\hline G5 & syn & 3 & 142.8 & 7.35 & 88.8 & 6.13 & 34.4 & 2.92 & 3.73 & 143.8 & 11.83 \\
\hline G6 & anti & 2 & 138.4 & 8.06 & 83.1 & 6.02 & 42.1 & 2.54 & 2.90 & 142.8 & 11.89 \\
\hline G7 & anti & 1 & 136.8 & 7.10 & 84.7 & 6.02 & 40.6 & 1.42 & 2.39 & 145.3 & 11.43 \\
\hline G11 & syn & 1 & 139.9 & 6.82 & 85.9 & 6.00 & 39.2 & 2.74 & 2.81 & 144.2 & 11.03 \\
\hline G12 & anti & 3 & 136.8 & 7.51 & 83.6 & 6.08 & 35.2 & 2.72 & 3.05 & 143.2 & 11.12 \\
\hline G13 & anti & 2 & 138.4 & 7.68 & 84.5 & 6.23 & 42.5 & 2.72 & 3.00 & 142.6 & 11.57 \\
\hline G14 & anti & 1 & 138.7 & 8.04 & 85.9 & 6.61 & 42.0 & 2.73 & 2.73 & 145.4 & 11.17 \\
\hline G16 & syn & 3 & 142.0 & 7.46 & 89.6 & 6.05 & 37.3 & 2.94 & 3.09 & 145.2 & 11.88 \\
\hline G17 & anti & 2 & 139.7 & 8.36 & 84.0 & 6.02 & 42.4 & 2.66 & 2.77 & 143.3 & 11.71 \\
\hline G18 & anti & 1 & 137.0 & 7.59 & 85.7 & 6.35 & 41.4 & 2.69 & 3.01 & 146 & 11.49 \\
\hline \multicolumn{12}{|c|}{$6 \mathrm{H} 1 \mathrm{~K}$} \\
\hline POSITION & G(anti) / G(syn) & PLANE & $\mathrm{C8}$ & H8 & C1' & H1' & C2' & $\mathbf{H}^{\prime}$ & H2" & N1 & H1 \\
\hline G1 & syn & 2 & 140.8 & 7.19 & 90.0 & 5.87 & 39.1 & 2.68 & 2.77 & $\mathrm{NaN}$ & 11.80 \\
\hline $\mathrm{G} 2$ & anti & 3 & 138.1 & 7.82 & 83.8 & 5.77 & 41.9 & 2.45 & 2.68 & $\mathrm{NaN}$ & 11.55 \\
\hline G15 & syn & 3 & 143.0 & 7.50 & 89.3 & 6.10 & $\mathrm{NaN}$ & $\mathrm{NaN}$ & $\mathrm{NaN}$ & $\mathrm{NaN}$ & 12.01 \\
\hline G16 & anti & 2 & 139.0 & 8.23 & 83.6 & 6.10 & $\mathrm{NaN}$ & $\mathrm{NaN}$ & $\mathrm{NaN}$ & $\mathrm{NaN}$ & 11.67 \\
\hline G17 & anti & 1 & 137.8 & 7.77 & 85.6 & 6.52 & $\mathrm{NaN}$ & $\mathrm{NaN}$ & $\mathrm{NaN}$ & $\mathrm{NaN}$ & 11.10 \\
\hline G19 & syn & 3 & 141.4 & 7.30 & 89.3 & 5.99 & $\mathrm{NaN}$ & $\mathrm{NaN}$ & $\mathrm{NaN}$ & $\mathrm{NaN}$ & 11.67 \\
\hline G20 & anti & 2 & 139.3 & 8.16 & 83.1 & 5.82 & $\mathrm{NaN}$ & $\mathrm{NaN}$ & $\mathrm{NaN}$ & $\mathrm{NaN}$ & 11.74 \\
\hline G21 & anti & 1 & 136.3 & 7.24 & 85.1 & 6.10 & $\mathrm{NaN}$ & $\mathrm{NaN}$ & $\mathrm{NaN}$ & $\mathrm{NaN}$ & 11.57 \\
\hline G25 & syn & 1 & 140.4 & 7.25 & 86.1 & 6.13 & $\mathrm{NaN}$ & $\mathrm{NaN}$ & $\mathrm{NaN}$ & $\mathrm{NaN}$ & 11.05 \\
\hline G26 & anti & 3 & 136.0 & 7.43 & 82.7 & 5.98 & $\mathrm{NaN}$ & $\mathrm{NaN}$ & $\mathrm{NaN}$ & $\mathrm{NaN}$ & 11.32 \\
\hline G27 & anti & 2 & 138.1 & 7.69 & 84.6 & 6.16 & $\mathrm{NaN}$ & $\mathrm{NaN}$ & $\mathrm{NaN}$ & $\mathrm{NaN}$ & 11.77 \\
\hline G28 & anti & 1 & 138.0 & 7.96 & 85.4 & 6.46 & $\mathrm{NaN}$ & $\mathrm{NaN}$ & $\mathrm{NaN}$ & $\mathrm{NaN}$ & 11.51 \\
\hline \multicolumn{12}{|c|}{ 2MFT } \\
\hline POSITION & G(anti) / G(syn) & PLANE & $\mathrm{C8}$ & H8 & C1' & H1' & C2' & $\mathbf{H 2}^{\prime}$ & H2" & N1 & H1 \\
\hline G1 & syn & 1 & 141.2 & 7.27 & 89.5 & 5.78 & 35.6 & 2.90 & 2.90 & 144.5 & 11.73 \\
\hline G2 & anti & 2 & 139.3 & 8.05 & 83.4 & 5.31 & 41.4 & 2.30 & 2.53 & 143.9 & 11.71 \\
\hline G3 & anti & 3 & 138.4 & 7.99 & 84.6 & 6.15 & 38.5 & 2.59 & 2.83 & 144.1 & 11.52 \\
\hline G8 & syn & 3 & 142.3 & 7.31 & 89.0 & 6.20 & 37.3 & 3.03 & 3.39 & 146.3 & 12.17 \\
\hline G9 & syn & 2 & 141.1 & 7.42 & 88.9 & 5.99 & 36.8 & 2.87 & 3.23 & 143.9 & 11.15 \\
\hline G10 & anti & 1 & 139.0 & 8.21 & 84.2 & 6.30 & 42.4 & 2.45 & 2.67 & 144.1 & 11.58 \\
\hline G12 & syn & 3 & 140.5 & 7.20 & 90.3 & 5.90 & 36.8 & 3.30 & 3.30 & 143.5 & 11.59 \\
\hline G13 & syn & 2 & 141.3 & 7.37 & 87.6 & 5.68 & 37.9 & 2.51 & 2.51 & 143.0 & 11.69 \\
\hline G14 & anti & 1 & 138.5 & 7.96 & 84.1 & 5.93 & 39.0 & 2.52 & 2.69 & 144.2 & 11.64 \\
\hline G19 & syn & 1 & 142.0 & 7.55 & 89.4 & 6.23 & 36.2 & 3.04 & 3.58 & 144.3 & 11.75 \\
\hline G20 & anti & 2 & 137.7 & 7.91 & 84.1 & 6.23 & 43.0 & 2.58 & 2.94 & 144.1 & 11.55 \\
\hline G21 & anti & 3 & 138.9 & 7.95 & 85.8 & 6.64 & 41.6 & 2.74 & 2.83 & 145.2 & 11.09 \\
\hline
\end{tabular}




\begin{tabular}{|c|c|c|c|c|c|c|c|c|c|c|c|}
\hline \multicolumn{12}{|c|}{$5 \mathrm{~J} 05$} \\
\hline POSITION & G(anti) / G(syn) & PLANE & C8 & H8 & C1' & H1' & $\mathrm{C2}^{\prime}$ & H2' & H2" & N1 & H1 \\
\hline G1 & syn & 1 & 141.7 & 7.42 & 90.0 & 5.83 & 38.2 & 2.67 & 2.88 & 145.2 & 12.10 \\
\hline G2 & anti & 2 & 139.1 & 8.21 & 83.3 & 5.64 & 40.3 & 2.55 & 2.61 & 145.6 & 12.14 \\
\hline G3 & syn & 3 & 141.0 & 7.90 & 87.7 & 6.37 & 41.4 & 2.81 & 2.85 & 144.0 & 11.37 \\
\hline G7 & anti & 3 & 139.6 & 8.16 & 83.1 & 5.84 & 38.0 & 2.66 & 3.32 & 142.1 & 10.88 \\
\hline G8 & syn & 2 & 142.2 & 7.61 & 88.0 & 5.91 & 36.8 & 2.67 & 2.69 & 144.8 & 11.48 \\
\hline G9 & anti & 1 & 138.9 & 8.01 & 84.3 & 5.92 & 38.9 & 2.53 & 2.70 & 143.3 & 11.33 \\
\hline G14 & syn & 1 & 141.9 & 7.51 & 88.9 & 6.14 & 36.2 & 2.95 & 3.47 & 144.3 & 11.89 \\
\hline G15 & anti & 2 & 136.8 & 7.57 & 84.3 & 6.17 & 43.1 & 2.67 & 2.85 & 144.4 & 11.30 \\
\hline G16 & syn & 3 & 142.2 & 7.94 & 86.5 & 6.32 & 39.3 & 2.65 & 3.01 & 142.5 & 11.11 \\
\hline G18 & anti & 3 & 138.2 & 7.96 & 84.4 & 6.04 & 39.6 & 2.59 & 2.87 & 143.5 & 11.30 \\
\hline G19 & syn & 2 & 141.6 & 7.39 & 89.5 & 6.05 & 34.3 & 2.89 & 3.61 & 142.5 & 10.87 \\
\hline G20 & anti & 1 & 139.2 & 8.32 & 84.2 & 6.35 & 42.0 & 2.48 & 2.76 & 144.0 & 11.57 \\
\hline \multicolumn{12}{|c|}{ 5YEY } \\
\hline POSITION & G(anti) / G(syn) & PLANE & C8 & H8 & C1' & H1' & C2' & H2' & H2" & N1 & H1 \\
\hline G1 & syn & 1 & 141.0 & 7.39 & 90.2 & 6.11 & 39.6 & 2.60 & 3.18 & 145.0 & 11.76 \\
\hline $\mathrm{G} 2$ & anti & 2 & 138.2 & 7.85 & 83.6 & 5.76 & 42.2 & 2.54 & 2.64 & 144.5 & 12.14 \\
\hline G3 & anti & 3 & 136.8 & 7.83 & 84.2 & 6.20 & 41.8 & 2.63 & 2.68 & 144.9 & 11.64 \\
\hline G7 & syn & 3 & 141.4 & 7.38 & 89.3 & 6.16 & 36.1 & 3.14 & 3.52 & 143.6 & 10.65 \\
\hline G8 & syn & 2 & 140.6 & 7.47 & 88.3 & 5.85 & 39.5 & 2.45 & 2.45 & 142.7 & 11.37 \\
\hline G9 & anti & 1 & 138.5 & 8.06 & 84.1 & 6.03 & 40.0 & 2.56 & 2.71 & 144.5 & 11.91 \\
\hline G13 & syn & 1 & 141.9 & 7.48 & 89.4 & 6.10 & 35.5 & 3.03 & 3.50 & 143.6 & 11.20 \\
\hline G14 & anti & 2 & 137.8 & 7.78 & 84.1 & 5.85 & 42.4 & 2.41 & 2.73 & 144.3 & 12.05 \\
\hline G15 & anti & 3 & 137.3 & 7.92 & 83.9 & 6.15 & 41.7 & 2.36 & 2.73 & 145.0 & 11.76 \\
\hline G19 & syn & 3 & 141.3 & 7.33 & 89.0 & 6.12 & 36.1 & 3.18 & 3.56 & 144.0 & 11.53 \\
\hline G20 & syn & 2 & 140.4 & 7.37 & 88.1 & 5.77 & 38.9 & 2.36 & 2.49 & 142.6 & 11.29 \\
\hline G21 & anti & 1 & 138.4 & 8.03 & 84.1 & 6.14 & 42.1 & 2.40 & 2.64 & 144.0 & 11.53 \\
\hline
\end{tabular}

\section{REFERENCES}

1. Webba da Silva, M., Geometric Formalism for DNA Quadruplex Folding. Chemistry - A European Journal 2007, 13 (35), 9738-9745. DOI: 10.1002/chem.200701255

2. Fogolari, F.; Haridas, H.; Corazza, A.; Viglino, P.; Corà, D.; Caselle, M.; Esposito, G.; Xodo, L. E., Molecular models for intrastrand DNA G-quadruplexes. BMC Struct Biol 2009, 9 (1), 64. DOI: $10.1186 / 1472-6807-9-64$

3. Lu, X.-J.; Bussemaker, H. J.; Olson, W. K., DSSR: an integrated software tool for dissecting the spatial structure of RNA. Nucleic Acids Research 2015, gkv716. DOI: 10.1093/nar/gkv716

4. Wang, Y.; Patel, D. J., Solution structure of the human telomeric repeat d[AG3(T2AG3)3] Gtetraplex. Structure 1993, 1 (4), 263-282. DOI: 10.1016/0969-2126(93)90015-9

5. Dai, J.; Punchihewa, C.; Ambrus, A.; Chen, D.; Jones, R. A.; Yang, D., Structure of the intramolecular human telomeric G-quadruplex in potassium solution: a novel adenine triple formation. Nucleic Acids Research 2007, 35 (7), 2440-2450. DOI: 10.1093/nar/gkm009 
6. Phan, A. T.; Kuryavyi, V.; Luu, K. N.; Patel, D. J., Structure of two intramolecular G-quadruplexes formed by natural human telomere sequences in K + solution. Nucleic Acids Research 2007, 35 (19), 6517-6525. DOI: 10.1093/nar/gkm706

7. Kuryavyi, V.; Phan, A. T.; Patel, D. J., Solution structures of all parallel-stranded monomeric and dimeric G-quadruplex scaffolds of the human c-kit2 promoter. Nucleic Acids Research 2010, 38 (19), 6757-6773. DOI: 10.1093/nar/gkq558

8. Liu, W.; Lin, C.; Wu, G.; Dai, J.; Chang, T.-C.; Yang, D., Structures of 1:1 and 2:1 complexes of BMVC and MYC promoter G-quadruplex reveal a mechanism of ligand conformation adjustment for G4-recognition. Nucleic Acids Research 2019, 47 (22), 11931-11942. DOI: 10.1093/nar/gkz1015

9. Amrane, S.; Adrian, M.; Heddi, B.; Serero, A.; Nicolas, A.; Mergny, J.-L.; Phan, A. T., Formation of Pearl-Necklace Monomorphic G-Quadruplexes in the Human CEB25 Minisatellite. J. Am. Chem. Soc. 2012, 134 (13), 5807-5816. DOI: 10.1021/ja208993r

10. Marquevielle, J.; Kumar, M. V. V.; Mergny, J.-L.; Salgado, G. F., 1H, 13C, and 15N chemical shift assignments of a G-quadruplex forming sequence within the KRAS proto-oncogene promoter region. Biomol NMR Assign 2018, 12 (1), 123-127. DOI: 10.1007/s12104-017-9793-0

11. Marquevielle, J.; Robert, C.; Lagrabette, O.; Wahid, M.; Bourdoncle, A.; Xodo, L. E.; Mergny, J.-L.; Salgado, G. F., Structure of two G-quadruplexes in equilibrium in the KRAS promoter. Nucleic Acids Research 2020, gkaa387. DOI: 10.1093/nar/gkaa387

12. Dickerhoff, J.; Onel, B.; Chen, L.; Chen, Y.; Yang, D., Solution Structure of a $<\mathrm{i}>\mathrm{MYC}</ \mathrm{i}>$ Promoter G-Quadruplex with 1:6:1 Loop Length. ACS Omega 2019, 4 (2), 2533-2539. DOI: 10.1021/acsomega.8b03580

13. Dickerhoff, J.; Haase, L.; Langel, W.; Weisz, K., Tracing Effects of Fluorine Substitutions on GQuadruplex Conformational Changes. ACS Chem. Biol. 2017, 12 (5), 1308-1315. DOI: 10.1021/acschembio.6b01096

14. Marušič, M.; Plavec, J., Towards Understanding of Polymorphism of the G-rich Region of Human Papillomavirus Type 52. Molecules 2019, 24 (7), 1294. DOI: 10.3390/molecules24071294

15. Dickerhoff, J.; Weisz, K., Nonconventional C-H $\cdots$ F Hydrogen Bonds Support a Tetrad Flip in Modified G-Quadruplexes. $J$ Phys Chem Lett 2017, 8 (20), 5148-5152. DOI: 10.1021/acs.jpclett.7b02428

16. Haase, L.; Dickerhoff, J.; Weisz, K., DNA-RNA Hybrid Quadruplexes Reveal Interactions that Favor RNA Parallel Topologies. Chemistry 2018, 24 (57), 15365-15371. DOI: 10.1002/chem.201803367

17. Haase, L.; Dickerhoff, J.; Weisz, K., Sugar Puckering Drives G-Quadruplex Refolding: Implications for V-Shaped Loops. Chemistry 2020, 26 (2), 524-533. DOI: 10.1002/chem.201904044

18. Karg, B.; Mohr, S.; Weisz, K., Duplex-Guided Refolding into Novel G-Quadruplex (3+1) Hybrid Conformations. Angew. Chem. Int. Ed. Engl. 2019, 58 (32), 11068-11071. DOI: 10.1002/anie.201905372

19. Haase, L.; Weisz, K., Switching the type of V-loop in sugar-modified G-quadruplexes through altered fluorine interactions. Chem. Commun. 2020, 56 (33), 4539-4542. DOI: 10.1039/D0CC01285H

20. Dickerhoff, J.; Weisz, K., Fluorine-Mediated Editing of a G-Quadruplex Folding Pathway. Chembiochem 2018, 19 (9), 927-930. DOI: 10.1002/cbic.201800099

21. Kerkour, A.; Mergny, J.-L.; Salgado, G. F., NMR based model of human telomeric repeat Gquadruplex in complex with 2,4,6-triarylpyridine family ligand. Biochimica et Biophysica Acta (BBA) - General Subjects 2017, 1861 (5), 1293-1302. DOI: 10.1016/j.bbagen.2016.12.016

22. Cavanagh, J.; Skelton, N.; Fairbrother, W.; Rance, M.; Palmer, I., Arthur, Protein NMR Spectroscopy - 2nd Edition. 2nd ed.; Elsevier: 2006; p 912.

23. Farjon, J.; Boisbouvier, J.; Schanda, P.; Pardi, A.; Simorre, J.-P.; Brutscher, B., LongitudinalRelaxation-Enhanced NMR Experiments for the Study of Nucleic Acids in Solution. J. Am. Chem. Soc. 2009, 131 (24), 8571-8577. DOI: 10.1021/ja901633y

24. Delaglio, F.; Grzesiek, S.; Vuister, G.; Zhu, G.; Pfeifer, J.; Bax, A., NMRPipe: A multidimensional spectral processing system based on UNIX pipes. $J$ Biomol NMR 1995, 6 (3). DOI: 10.1007/BF00197809 
25. Lee, W.; Tonelli, M.; Markley, J. L., NMRFAM-SPARKY: enhanced software for biomolecular NMR spectroscopy. Bioinformatics 2015, 31 (8), 1325-1327. DOI: 10.1093/bioinformatics/btu830

26. Ambrus, A.; Chen, D.; Dai, J.; Jones, R. A.; Yang, D., Solution Structure of the Biologically Relevant G-Quadruplex Element in the Human c-MYC Promoter. Implications for G-Quadruplex Stabilization $<$ sup $>\uparrow</$ sup $>$. Biochemistry 2005, 44 (6), 2048-2058. DOI: 10.1021/bi048242p

27. Marušič, M.; Šket, P.; Bauer, L.; Viglasky, V.; Plavec, J., Solution-state structure of an intramolecular G-quadruplex with propeller, diagonal and edgewise loops. Nucleic Acids Research 2012, 40 (14), 6946-6956. DOI: 10.1093/nar/gks329

28. Luu, K. N.; Phan, A. T.; Kuryavyi, V.; Lacroix, L.; Patel, D. J., Structure of the Human Telomere in K+ Solution: An Intramolecular (3+1) G-Quadruplex Scaffold. J. Am. Chem. Soc. 2006, 128 (30), 9963-9970. DOI: 10.1021/ja062791w

29. Wang, Y.; Patel, D. J., Solution structure of the Tetrahymena telomeric repeat d(T2G4)4 G-tetraplex. Structure 1994, 2 (12), 1141-1156. DOI: 10.1016/S0969-2126(94)00117-0

30. Dai, J.; Carver, M.; Punchihewa, C.; Jones, R. A.; Yang, D., Structure of the Hybrid-2 type intramolecular human telomeric G-quadruplex in $\mathrm{K}+$ solution: insights into structure polymorphism of the human telomeric sequence. Nucleic Acids Research 2007, 35 (15), 4927-4940. DOI: $10.1093 / \mathrm{nar} / \mathrm{gkm} 522$

31. Dai, J.; Chen, D.; Jones, R. A.; Hurley, L. H.; Yang, D., NMR solution structure of the major Gquadruplex structure formed in the human BCL2 promoter region. Nucleic Acids Research 2006, 34 (18), 5133-5144. DOI: 10.1093/nar/gk1610

32. Sengar, A.; Vandana, J. J.; Chambers, V. S.; Di Antonio, M.; Winnerdy, F. R.; Balasubramanian, S.; Phan, A. T., Structure of a $(3+1)$ hybrid G-quadruplex in the PARP1 promoter. Nucleic Acids Research 2019, 47 (3), 1564-1572. DOI: 10.1093/nar/gky1179

33. Kuryavyi, V.; Patel, D. J., Solution structure of a unique G-quadruplex scaffold adopted by a guanosine-rich human intronic sequence. Structure 2010, 18 (1), 73-82. DOI: 10.1016/j.str.2009.10.015

34. Butovskaya, E.; Heddi, B.; Bakalar, B.; Richter, S. N.; Phan, A. T., Major G-Quadruplex Form of HIV-1 LTR Reveals a $(3+1)$ Folding Topology Containing a Stem-Loop. J. Am. Chem. Soc. 2018, 140 (42), 13654-13662. DOI: 10.1021/jacs.8b05332

35. Dvorkin, S. A.; Karsisiotis, A. I.; Webba da Silva, M., Encoding canonical DNA quadruplex structure. Sci. $A d v$. 2018, 4 (8), eaat3007. DOI: 10.1126/sciadv.aat3007

36. Liu, C.; Zhou, B.; Geng, Y.; Yan Tam, D.; Feng, R.; Miao, H.; Xu, N.; Shi, X.; You, Y.; Hong, Y.; Tang, B. Z.; Kwan Lo, P.; Kuryavyi, V.; Zhu, G., A chair-type G-quadruplex structure formed by a human telomeric variant DNA in $\mathrm{K}^{+}$solution. Chem. Sci. 2019, 10 (1), 218-226. DOI: 10.1039/C8SC03813A

37. Ivanciuc, O., Applications of Support Vector Machines in Chemistry. In Reviews in Computational Chemistry, John Wiley \& Sons, Ltd: 2007; pp 291-400. 